\title{
Vertical profiling of aerosol hygroscopic properties in the planetary boundary layer during the PEGASOS campaigns
}

\author{
Bernadette Rosati $^{1, \mathrm{a}}$, Martin Gysel ${ }^{1}$, Florian Rubach ${ }^{2,3, \mathrm{~b}}$, Thomas F. Mentel ${ }^{2}$, Brigitta Goger ${ }^{1, \mathrm{c}}$, Laurent Poulain ${ }^{3}$, \\ Patrick Schlag $^{2}$, Pasi Miettinen ${ }^{4}$, Aki Pajunoja ${ }^{4}$, Annele Virtanen ${ }^{4}$, Henk Klein Baltink ${ }^{5}$, J. S. Bas Henzing ${ }^{6}$, \\ Johannes Größ $^{3}$, Gian Paolo Gobbi ${ }^{7}$, Alfred Wiedensohler ${ }^{3}$, Astrid Kiendler-Scharr ${ }^{2}$, Stefano Decesari ${ }^{8}$, \\ Maria Cristina Facchini ${ }^{8}$, Ernest Weingartner ${ }^{1, \mathrm{~d}}$, and Urs Baltensperger ${ }^{1}$ \\ ${ }^{1}$ Laboratory of Atmospheric Chemistry, Paul Scherrer Institute (PSI), 5232 Villigen, Switzerland \\ ${ }^{2}$ Institute for Energy and Climate Research (IEK-8), Forschungszentrum Jülich, 52428 Jülich, Germany \\ ${ }^{3}$ Leibniz Institute for Tropospheric Research, 04318 Leipzig, Germany \\ ${ }^{4}$ Department of Applied Physics, University of Eastern Finland, 1627 Kuopio, Finland \\ ${ }^{5}$ Royal Netherlands Meteorological Institute (KNMI), 3730 De Bilt, the Netherlands \\ ${ }^{6}$ Netherlands Organization for Applied Scientific Research (TNO), 80015 Utrecht, the Netherlands \\ ${ }^{7}$ Institute of Atmospheric Sciences and Climate (ISAC-CNR), National Research Council, 00133 Rome, Italy \\ ${ }^{8}$ Institute of Atmospheric Sciences and Climate (ISAC-CNR), National Research Council, 40129 Bologna, Italy \\ ${ }^{a}$ now at: Institute for Aerosol Physics and Environmental Physics, University of Vienna, 1090 Vienna, Austria \\ bnow at: Max Planck Institute for Chemistry, 55128 Mainz, Germany \\ ${ }^{c}$ now at: Institute of Meteorology and Geophysics, University of Innsbruck, 6020 Innsbruck, Austria \\ dnow at: Institute for Aerosol and Sensor Technology, University of Applied Science Northwestern Switzerland, \\ 5210 Windisch, Switzerland
}

Correspondence to: Martin Gysel (martin.gysel@psi.ch)

Received: 26 January 2015 - Published in Atmos. Chem. Phys. Discuss.: 31 March 2015

Revised: 13 May 2016 - Accepted: 23 May 2016 - Published: 10 June 2016

\begin{abstract}
Vertical profiles of the aerosol particles hygroscopic properties, their mixing state as well as chemical composition were measured above northern Italy and the Netherlands. An aerosol mass spectrometer (AMS; for chemical composition) and a white-light humidified optical particle spectrometer (WHOPS; for hygroscopic growth) were deployed on a Zeppelin NT airship within the PEGASOS project. This allowed one to investigate the development of the different layers within the planetary boundary layer (PBL), providing a unique in situ data set for airborne aerosol particles properties in the first kilometre of the atmosphere. Profiles measured during the morning hours on 20 June 2012 in the Po Valley, Italy, showed an increased nitrate fraction at $\sim 100 \mathrm{~m}$ above ground level (a.g.l.) coupled with enhanced hygroscopic growth compared to $\sim 700 \mathrm{~m}$ a.g.l. This result was derived from both measurements of the aerosol composition and direct measurements of the hygroscopicity, yielding hygroscopicity parameters $(\kappa)$ of $0.34 \pm 0.12$ and
\end{abstract}

$0.19 \pm 0.07$ for $500 \mathrm{~nm}$ particles, at $\sim 100$ and $\sim 700 \mathrm{~m}$ a.g.l., respectively. The difference is attributed to the structure of the PBL at this time of day which featured several independent sub-layers with different types of aerosols. Later in the day the vertical structures disappeared due to the mixing of the layers and similar aerosol particle properties were found at all probed altitudes (mean $\kappa \approx 0.18 \pm 0.07$ ). The aerosol properties observed at the lowest flight level (100 ma.g.l.) were consistent with parallel measurements at a ground site, both in the morning and afternoon. Overall, the aerosol particles were found to be externally mixed, with a prevailing hygroscopic fraction. The flights near Cabauw in the Netherlands in the fully mixed PBL did not feature altitude-dependent characteristics. Particles were also externally mixed and had an even larger hygroscopic fraction compared to the results in Italy. The mean $\kappa$ from direct measurements was $0.28 \pm 0.10$, thus considerably higher than $\kappa$ values measured in Italy in the fully mixed PBL. 


\section{Introduction}

Aerosol particles directly have an impact on climate by absorbing or scattering the solar radiation. The optical properties depend on the particles' size as well as their chemical composition and both can be altered at elevated relative humidities (RH) if the particles are hygroscopic (Boucher et al., 2013).

Most particles are emitted or formed in the planetary boundary layer (PBL), the lowermost layer of the troposphere. The PBL is subject to changes depending on the strength of the incident solar radiation (compare Stull, 1988): under clear sky conditions heating of the Earth's surface by solar radiation induces convective turbulence and therefore a well-mixed PBL builds up after midday ranging up to an altitude of approximately $2 \mathrm{~km}$. During night when the surface cools down, several sub-layers are present in the PBL where the uppermost part is defined as the residual layer (RL). The RL contains a mixture of emissions and background aerosol from the day before and is decoupled from the surface. Close to the ground a stable nocturnal layer (NL) develops where local and/or regional emissions accumulate. Once the sun rises a new mixing layer (ML) is formed which is separated from the other layers through a temperature inversion. Throughout the day this ML evolves until it reaches up to the free troposphere and extends across the whole PBL. The dynamics of the sub-layers in the PBL and its effect on the properties of the aerosol particles in these layers are still poorly understood.

Airborne studies were previously performed to investigate the aerosol chemical composition as a function of altitude utilizing an aerosol mass spectrometer and showing that chemical composition varies with height (Morgan et al., 2009, 2010a, b; Pratt and Prather, 2010). Accordingly, aerosol hygroscopicity, which depends on chemical composition and can also be inferred from it, is also expected to be height dependent. Morgan et al. (2010a) conducted flights over north-western Europe, focusing on changes between 0 and $10 \mathrm{~km}$ a.g.l. In general aircraft campaigns commonly stretch over large areas and altitudes, often above the PBL, therefore providing only limited information on the PBL itself. On the other hand, extensive data sets studying the variability of aerosol composition and hygroscopic properties are available from ground-based studies. However, surface measurements are not always representative for aerosol properties at elevated altitudes.

One way to explore the hygroscopic properties of aerosols is to measure the so-called hygroscopic growth factor (GF) defined as the ratio of the particle diameter at a certain relative humidity (RH; $\left.D_{\text {wet }}\right)$ divided by its dry diameter $\left(D_{\text {dry }}\right)$ :

$\mathrm{GF}(\mathrm{RH})=\frac{D_{\mathrm{wet}}(\mathrm{RH})}{D_{\text {dry }}}$.

The most common instrument for ground-based hygroscopicity measurements of atmospheric aerosol particles is the hygroscopicity tandem differential mobility analyzer (HTDMA; see e.g. Liu et al., 1978, or McMurry and Stolzenburg, 1989, for details). It explores particle growth in the subsaturated RH range and was employed successfully in several ground-based campaigns (compare the review by Swietlicki et al., 2008). This method investigates GFs at high precision but needs several minutes for a full measurement cycle which makes it rather unsuited for airborne measurements. Besides, its detection range is limited to a maximal dry mobility diameter of approximately $250 \mathrm{~nm}$. HTDMA and chemical composition hygroscopicity closures were performed at various sites including urban (see e.g. Kamilli et al., 2014) and rural regions (see e.g. Wu et al., 2013), as well as elevated mountain sites (e.g. Kammermann et al., 2010).

To our knowledge, only few campaigns report airborne hygroscopicity results due to the lack of suitable instruments for this kind of measurements. The first instrument built for this special task is the aerosol hydration spectrometer (AHS; Hegg et al., 2007). The set-up comprises two optical instruments, to measure the properties of the dry and humidified aerosol particles. However, quantifying hygroscopic growth with the AHS is difficult as the measurement is performed for poly-disperse rather than size-selected aerosol samples. The differential aerosol sizing and hygroscopicity spectrometer probe (DASH-SP; Sorooshian et al., 2008) is using a combination of differential mobility analysis (DMA) and optical particle spectrometry (OPS) and has successfully been applied for airborne GF measurements at sub-saturated RH. This instrument is limited to small sizes in the range of $150-225 \mathrm{~nm}$ dry diameters. In the aircraft campaigns an attempt was made to reconcile simultaneously measured chemical composition and hygroscopic growth using an AMS and DASH-SP. Herein, Hersey et al. $(2009,2013)$ focused their studies on the free troposphere in the marine atmosphere off the coast of California.

Most measurement techniques to study hygroscopicity select particles smaller than $\sim 300 \mathrm{~nm}$, which implies that species that are more abundant at larger sizes (e.g. sea salt, mineral dust) cannot be easily investigated. This may induce a bias in estimates of the humidity effects on hygroscopic growth and light scattering efficiency of particles in the upper accumulation mode size range. Indeed, Zieger et al. (2011) presented a comparison between HTDMA measurements for dry diameters of $165 \mathrm{~nm}$ and calculated GFs using size distributions, scattering enhancement factors (based on polydisperse aerosol particles in the $\mathrm{PM}_{1}$ range) and Mie theory. The comparison revealed that indeed in the presence of sea salt the HTDMA hygroscopicity results for particle diameters of $165 \mathrm{~nm}$ were not representative for the atmospheric accumulation mode particles, finding too small GF values. Based on these findings we concluded that understanding the hygroscopic properties of larger particles is important as well to understand the RH effects on aerosol optical properties. Hence, we developed the white-light humidified optical particle spectrometer (WHOPS; Rosati et al., 2015) to perform 


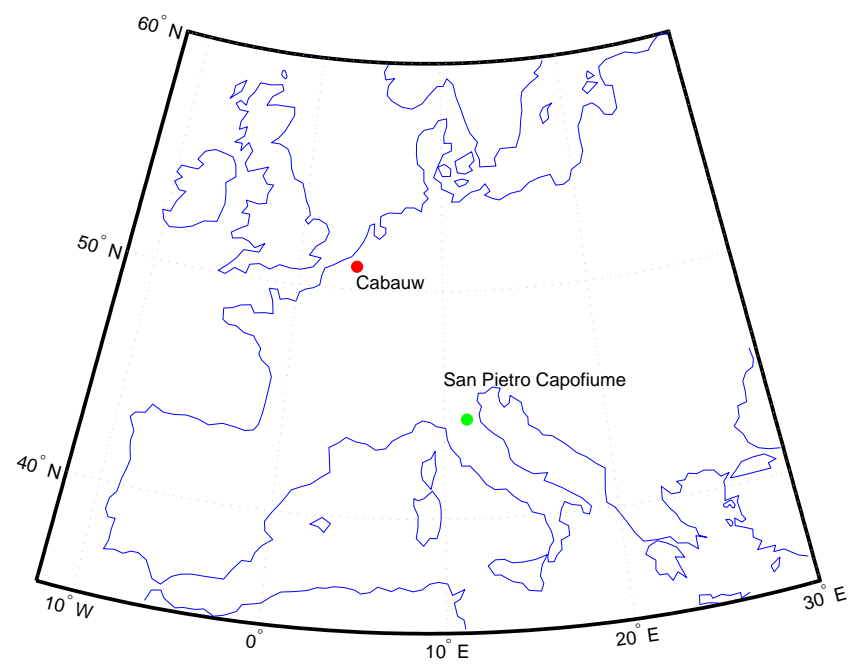

Figure 1. Map showing the different measurement sites in Europe: Cabauw located in the Netherlands (red dot) and San Pietro Capofiume (green dot) located in the Po Valley in Italy.

vertical profiles of the particles' hygroscopic properties of optically more relevant sizes $\left(D_{\mathrm{dry}}=300,500 \mathrm{~nm}\right)$.

Within the Pan-European Gas-AeroSOl-climate interaction Study (PEGASOS) air masses over Europe were explored in order to understand feedbacks between atmospheric chemistry and a changing climate. Our interest here focusses on the vertical changes in aerosol properties and particularly on changes occurring due to the dynamics of the PBL. For this purpose a Zeppelin NT ("New Technology") was utilized as a measurement platform to probe different layers present in the evolving convective PBL in various European regions. The Zeppelin NT airship was equipped with an aethalometer, an HR-ToF-AMS and the WHOPS to investigate the chemical composition, the hygroscopic properties as well as the mixing state of the aerosol particles. In the current study, data from vertical profiles recorded above southern (Po Valley, Italy) and central Europe (Cabauw, Netherlands) are presented (Fig. 1 shows the campaign locations). Comparison with co-located ground-based in situ measurements made it possible to assess under which conditions the ground data are representative of the column above.

\section{Experimental}

\subsection{The Zeppelin NT airship}

The Zeppelin NT airship, which served as a platform for the airborne measurements, flew with an average speed of $50 \mathrm{~km} \mathrm{~h}^{-1}$ a.g.l. and reached altitudes between 80 and $1000 \mathrm{~m}$ a.g.l., depending on the payload and ambient temperature. Therefore, a good spatial and temporal resolution of the gas-phase and aerosol properties could be obtained. This made it possible to focus on the evolution of the mixed layer forming at low altitudes in the first hours of sunlight and finally expanding across the whole PBL. In order to do so, circles at selected constant heights were flown with straight ascents and descents. For flight safety reasons, the Zeppelin could only be deployed on days with low wind speeds and low cloud coverage or clear sky.

The Zeppelin NT airship could be equipped with different instrumental layouts for focusing on certain research questions. For this study the so-called secondary organic aerosol (SOA) layout was utilized. This layout included measurements of aerosol properties like aerosol hygroscopicity, size distribution, particle number concentration, chemical composition and volatile organic compounds (VOC). The specific instruments used to measure these properties are described in the following subsections. In addition, nitrogen oxides $\left(\mathrm{NO}_{\mathrm{x}}\right)$, ozone $\left(\mathrm{O}_{3}\right)$, carbon monoxide $(\mathrm{CO})$, radiative flux, hydroxy as well as peroxy radicals $\left(\mathrm{OH}, \mathrm{HO}_{2}\right)$ were monitored continuously on board of the airship. Each instrument had a separate inlet system and a separate sampling position.

\subsection{Flight and ground-based measurement locations}

\subsubsection{Po Valley site}

The Italy campaign took place in the Po Valley, a region known for its remarkably high air pollution levels, compared to other places in Europe (see e.g. Putaud et al., 2010). The Po Valley hosts several industrial, urban and agricultural areas allowing for detailed anthropogenic pollution studies; however, long-range transport and aged aerosol from other sites can also be investigated. The Zeppelin NT airship was stationed at Ozzano Airport (located at $44^{\circ} 28^{\prime} \mathrm{N}, 11^{\circ} 32^{\prime} \mathrm{E}$, $\sim 30 \mathrm{~km}$ south-east of Bologna) and performed flights during June and July 2012 in the greater Po Valley region. The vertical profiles were mostly taken near the San Pietro Capofiume (SPC) ground station (located at $44^{\circ} 39^{\prime} \mathrm{N}, 11^{\circ} 38^{\prime} \mathrm{E}$ ), a rural background site which lies approximately $40 \mathrm{~km}$ northeast of Bologna. Throughout the PEGASOS campaign the SPC station was equipped with a set of instruments equivalent to those on the Zeppelin NT airship in order to compare flight and ground-level data. To get estimates of the mixing layer height a Jenoptik CHM15K "Nimbus" automated lidar ceilometer was employed at SPC. In the present analysis we used an operator-driven approach which avoids the major drawbacks of automated mixing layer height (MLH) retrievals (e.g., Angelini et al., 2009; Haeffelin et al., 2012; Di Giuseppe et al., 2012). This is performed by manually evaluating the MLH by a skilled operator's visual analysis. The trained operator manually marks a number of points (at least one per hour) matching the requirements of showing maximum signal gradients, maximum signal variance, continuity between sunrise until sunset and separation from the residual layer's gradient maxima. A spline curve is then fitted to these points to provide a continuous MLH over time. Naturally, the MLH is not retrieved when it descends be- 
low the minimum height observed by the ceilometer (about 200 ma.g.l.). The typical uncertainty due to this approach amounts to 3 pixels, i.e. $\pm 45 \mathrm{~m}$. Additionally, we compared the ceilometer retrieval to the MLH found by analysing $T$ and $\mathrm{RH}$ gradients from a co-located radio sounding performed at 11:00 UTC. Note that the radio sounding was carried out only once every $12 \mathrm{~h}$, while ceilometer retrievals of MLH have a time resolution of minutes. The 11:00 UTC MLH retrieved from the radio sounding yielded a value of $753 \mathrm{~m}$ a.g.l., while an altitude of $772 \mathrm{ma.g} .1$. was found from the ceilometer data at this time of day. The two retrievals agree within the $\pm 45 \mathrm{~m}$ we commonly use as uncertainty of our MLH retrievals. The findings of the ceilometer are additionally supported by height profiles of the potential temperature $(\Theta)$ measured aboard the Zeppelin NT, which can be found in the Supplement.

\subsubsection{Netherlands site}

The campaign in the Netherlands was located in the South Holland and Utrecht region. This region is representative for north-west Europe and is influenced by continental and maritime air masses, depending on the wind direction. The Zeppelin NT airship was stationed at Rotterdam - The Hague Airport and conducted several flights in May 2012. The vertical profiles were performed near the Cabauw Experimental Site for Atmospheric Research (CESAR, located at $51^{\circ} 97^{\prime} \mathrm{N}$, $4^{\circ} 93^{\prime} \mathrm{E}$ ). The CESAR station hosts a number of instruments to characterize radiative properties, climate monitoring and atmospheric processes (www.cesar-observatory.nl). During the PEGASOS campaign an aerosol mass spectrometer was added to the permanently installed aerosol measurements. Also at this station, a ceilometer system (Vaisala LD40) was utilized to get an estimated mixing layer height. The retrieval of the mixing layer height from the LD40 ceilometer backscatter profiles is based on a wavelet algorithm (Haij et al., 2007). The algorithm determines the height of the maximum in the gradient in the backscatter profile. The difference in backscatter in a small range below and above the retrieved height is used as an estimator for the quality of the retrieved height. Retrieved mixing heights with the highest quality index have comparable accuracy to radiosonde retrieved heights and have an estimated accuracy on the order of $\pm 50 \mathrm{~m}$.

\subsection{Instrumentation for aerosol measurements}

\subsubsection{Hygroscopic and optical aerosol properties}

On the Zeppelin the white-light humidified optical particle spectrometer (WHOPS) was used to determine hygroscopic GF. All instrument specifications, as well as associated calibration and data analysis procedures, are presented in detail in Rosati et al. (2015). Briefly, particles are collected through an isokinetic inlet, developed for an average flight velocity of $50 \mathrm{~km} \mathrm{~h}^{-1}$, before they reach the WHOPS. Then the particles are dried $(\mathrm{RH}<10 \%)$ and size-selected in a differential mobility analyzer (DMA). In a next step, the dry particles are guided directly to a WELAS 2300 optical particle spectrometer (WELAS; Palas GmbH, Karlsruhe, Germany) to measure the dry optical response. Alternatively, the size-selected dry particles are humidified before being directed to the WELAS to measure the wet optical response (residence time at high RH: $\sim 20$ s). Multiply charged particles appear as a distinctly separated mode in the optical size distribution measured by the WELAS and are discarded from the further data analysis. Hygroscopicity measurements are typically performed at $\mathrm{RH}=95 \%$, where the uncertainty in the humidity measurement is estimated to be $\pm 2 \%$. Since the RH to which particles were exposed to varied only between 94 and $96 \%$ during both flight days, no further RH corrections were applied to the results. Using the WHOPS set-up, an optically measured size distribution can be achieved by stepwise recording the size-selected particles in their dry and humidified state. To be able to link the measured partial scattering cross sections ( $\sigma$; from now on referred to as simply scattering cross section) of the WELAS to specific geometric diameters, several factors have to be known: the index of refraction $(m)$ as well as the optical set-up of the instrument, the spectrum of the light source and the sensitivity of the detector.

The WELAS was chosen because of its white-light source (OSRAM XBO-75 xenon short arc lamp) which minimizes Mie oscillations of the scattering cross section as a function of particle size. This allows for mostly unambiguous attribution of particle diameter to measured scattering cross section. Residual uncertainties with regard to the Mie oscillations amount to less than $7 \%$ in the GF (for more details see Rosati et al., 2015). Since specific dry mobility diameters were selected, the optically measured $\sigma$ can be converted to optical diameters $(D)$ using a $\sigma-D-m$ table for a series of different indices of refraction calculated based on Mie theory (Mie, 1908; Bohren and Huffman, 2007). The index of refraction for which the optical diameter of the dry particles coincides with the selected mobility diameter is then defined as the effective index of refraction $\left(m_{\mathrm{dry}}\right)$ of the dry particles. The qualifier "effective" is used because the true index of refraction can be slightly different due to required approximations such as assuming an imaginary part of zero and only spherical and homogeneously internally mixed particles (see Rosati et al., 2015, for more details).

The index of refraction of the grown particles approaches the index of refraction of pure water $\left(m_{\mathrm{H}_{2} \mathrm{O}}=1.333\right)$ with increasing hygroscopic GF. Including this effect is crucial for the data analysis and the approach was done as detailed in Rosati et al. (2015). The effective indices of refraction for $500 \mathrm{~nm}$ particles and a wavelength range of $380-600 \mathrm{~nm}$ (see Rosati et al., 2015 for the light spectrum of the WELAS) were found to be $1.43 \pm 0.02$ (mean \pm SD) in Italy and $1.42 \pm 0.02$ (mean $\pm \mathrm{SD}$ ) in the Netherlands. An absolute uncertainty of \pm 0.04 has to considered for all index of 


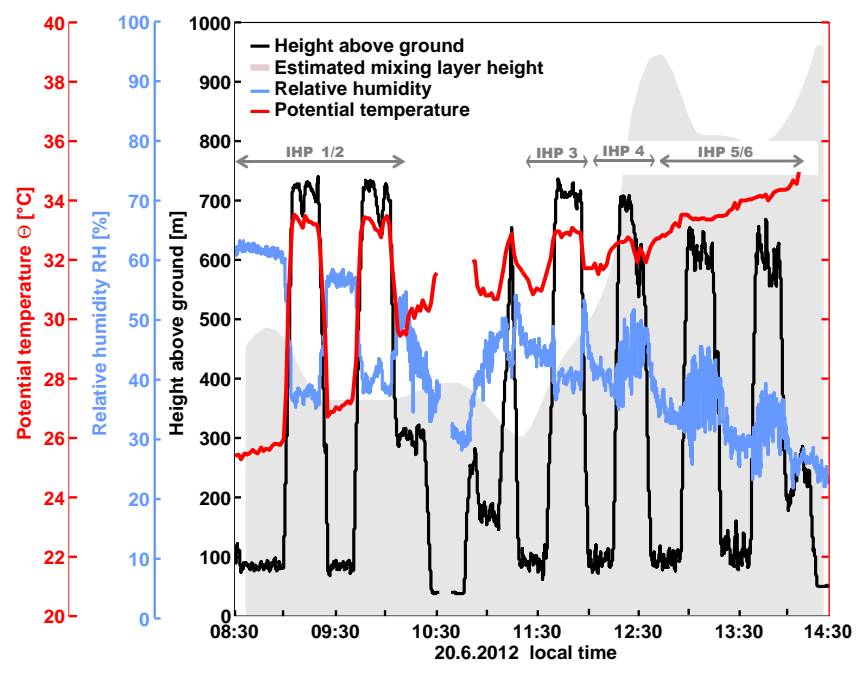

Figure 2. Overview of the flight on 20 June 2012 near San Pietro Capofiume ground station (Po Valley, Italy). In black the flight altitude and in grey the estimated mixing layer height, determined from ceilometer-Lidar measurements, are presented. The red and blue lines show the potential temperature $\Theta$ and RH profiles, respectively. In addition, the different height profiles IHP1/2, IHP3, IHP4 and IHP5/6 are indicated.

refraction retrievals (see Rosati et al., 2015 and Supplement). During the measurement campaigns, the instrument was regularly checked and calibrated with well-defined aerosols with known optical properties and hygroscopicity, e.g. ammonium sulphate particles. For such measurements no nonhygroscopic mode (GF $\sim 1$ ) was detected, as expected. However, the WHOPS, which uses a combination of mobility sizing and optical sizing, could potentially falsely classify certain particles as non-hygroscopic if they are non-spherical or if their index of refraction deviates substantially from the effective index of refraction applied in the data analysis approach. For example, moderately coated black carbon particles could be falsely classified. However, it is rather unlikely that the biases from selecting by mobility and optical sizing compensate each other in such a manner that the majority of the black-carbon-containing particles falsely appear to be non-hygroscopic.

Particles with a dry mobility diameter of 300 or $500 \mathrm{~nm}$ were alternately probed during $250 \mathrm{~s}$ per size, whereof $150 \mathrm{~s}$ was used for the wet mode and $100 \mathrm{~s}$ for the dry mode. The results were averaged for each probed layer at a constant flight altitude. This ensured that each GF-probability density function (GF-PDF) shown in Figs. 3, 4, 11 and 12 is based on more than 90 detected particles. As described in Rosati et al. (2015) the GF uncertainty for dry particle diameters of $500 \mathrm{~nm}$ is approximately $\pm 10 \%$ in the range $1<\mathrm{GF}<3$. Note that due to insufficient detection efficiency and ambiguous sizing in the optical detection the WHOPS can unambiguously detect particles with a dry diameter of $300 \mathrm{~nm}$ and a GF $>1.5$, whereas ambiguities occur for $\mathrm{GF}<1.5$ and
$D_{\text {dry }}=300 \mathrm{~nm}$, as described in Rosati et al. (2015). Thus, no information is available from the WHOPS measurements on the number fraction and properties of the $300 \mathrm{~nm}$ particles with $\mathrm{GF}<1.5$.

The distribution of GF can provide information on the mixing state of aerosol particles with respect to components that differ in hygroscopicity. Commonly the mixing state of aerosol particles is classified as follows: if all particles of a certain size have almost the same chemical composition, they are described as internally mixed, whereas if particles of equal size have different chemical composition, they are referred to as externally mixed. Depending on the mixture, the hygroscopic behaviour will change: internally mixed aerosols will grow uniformly with increasing $\mathrm{RH}$, while external mixtures of substances with differing hygroscopic properties will result in multi-modal and/or broadened GF distributions. We chose GF-PDFs as graphical representation of WHOPS data to investigate the mixing state of the aerosol particles during the flight days.

The SPC site was equipped with a hygroscopicity tandem differential mobility analyzer (HTDMA) in order to determine the hygroscopic properties of particles with four different dry diameters between 35 and $200 \mathrm{~nm}$. Each scan to record a GF-PDF at a fixed dry size lasted $500 \mathrm{~s}$ in total, thus providing a time resolution of 1.8 measurements per hour for each dry size. The set-up comprises two DMAs connected in series combined with a condensation particle counter (CPC). First, a dry mono-disperse aerosol is selected in the first DMA ( $\mathrm{RH}<30 \%)$, then exposed to elevated relative humidity (typically $90 \%$ ) and the resulting size distribution is then measured using a second DMA coupled to a CPC providing a GF distribution. The inversion of the HTDMA results was done with the algorithm proposed by Gysel et al. (2009). For a direct comparison to the WHOPS measurements, the HTDMA GF-PDF were recalculated for $\mathrm{RH}=95 \%$ using Eq. (5) in Gysel et al. (2009). Note that the dry sizes selected by the WHOPS are larger compared to those selected by the HTDMA, which is built for the investigation of smaller particles.

\subsubsection{Aerosol chemical composition}

A high-resolution time-of-flight aerosol mass spectrometer (HR-ToF-AMS; DeCarlo et al., 2006) was employed to characterize the non-refractory chemical composition of aerosol particles. The term non-refractory refers to all species that flash vaporize at $600{ }^{\circ} \mathrm{C}$ and $\sim 10^{-7}$ Torr. The particles were sampled through a $1500 \mathrm{~mm}$ long tube (4 mm ID), ending about $200 \mathrm{~mm}$ below the bottom hatch of the Zeppelin. A constant pressure inlet, consisting of an orifice that is pumped with variable flow and installed between the aerosol inlet and the AMS, was used to regulate the downstream pressure to $800 \mathrm{hPa}$ independent of upstream pressure. This ensured constant sampling conditions for the AMS. Within the AMS, the particles pass a critical orifice and an aerodynamic lens, 
ITALY
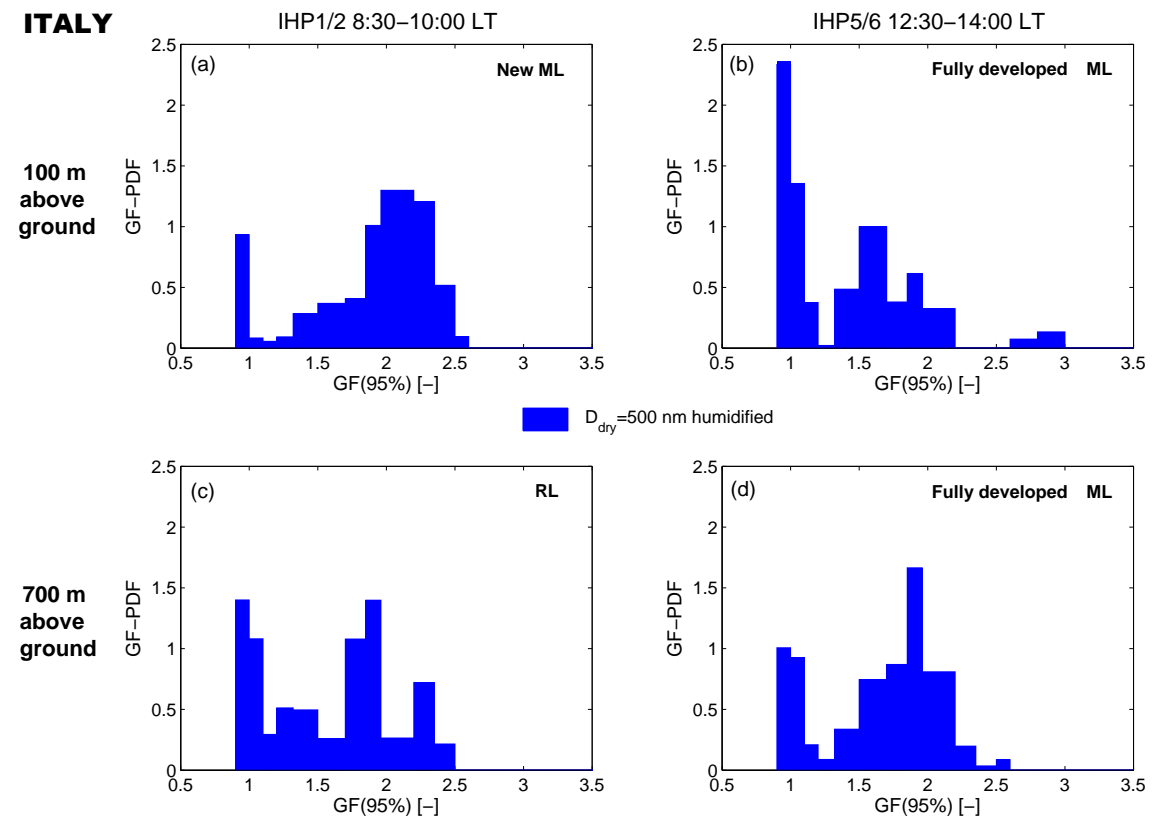

Figure 3. GF-PDFs during 20 June 2012 in Italy: profile IHP1/2 was flown between 08:30 and 10:00 LT and IHP5/6 between $\sim 12: 30$ and 14:00 LT; the blue area displays the GF-PDFs for a selected dry diameter of $500 \mathrm{~nm}$. (a, b) illustrate the results at approximately $100 \mathrm{ma.g} .1$. and (c, d) for approximately $700 \mathrm{~m}$ a.g.l.

which collimates particles of sizes between 100 and $700 \mathrm{~nm}$ into a narrow beam. The particle beam is impinging on a hot surface $\left(600^{\circ} \mathrm{C}\right)$, where the non-refractory components flash vaporize. The resulting vapours are ionized by electron impact ionization and measured with a time-of-flight mass spectrometer. The AMS allows for identification and quantification of peaks corresponding to classes of chemical species (e.g. nitrates, sulphates, chloride, ammonia and organics). Where mass resolution is not sufficient or more than one chemical species fragments to the same ion in the ionization process, known relationships between peaks at different mass to charge ratios are used to improve quantification (fragmentation table, Allan et al., 2004). Two operational modes of the ToF-MS (V- and W-Mode) were used during the flights. Specifications of the adaptation of the HR-ToF-AMS for the Zeppelin requirements can be found in Rubach (2013). A collection efficiency (CE) of 1 was applied to the AMS measurements, based on a comparison between mass concentrations derived from particle size distributions measured by scanning mobility particle sizers (SMPS; TSI Inc., DMA Model 3081 and water - CPC Model 3786) and WELAS, and the combined results of AMS and aethalometer measurements on the Zeppelin. Because a CE of 1 is higher than observed in other field studies and we cannot explain this difference, we attribute an uncertainty of $\sim 50 \%$ for the Zeppelin AMS mass concentrations. The same procedure was applied to the ground measurements at SPC yielding the same conclusion that a CE of 1 has to be used. In Cabauw the CE was estimated using the algorithm proposed by Middlebrook et al.
(2012). The mass fractions of the compounds are independent of this uncertainty.

At the ground stations, both in Italy and the Netherlands, equivalent black carbon (eBC) mass concentrations were measured with a multi-angle absorption photometer (MAAP Thermo Scientific Model 5012; Petzold et al., 2005) with a resolution of $5 \mathrm{~min}$ and an uncertainty of $12 \%$ (Petzold and Schönlinner, 2004). A mass absorption cross section (MAC) of $6.6 \mathrm{~m}^{2} \mathrm{~g}^{-1}$ for a wavelength of $637 \mathrm{~nm}$ (Müller et al., 2011) was chosen to convert the measured particle absorption coefficient to eBC mass concentrations. A portable aethalometer (AE42, MAGEE Scientific; Berkeley, USA) was mounted on the Zeppelin NT to monitor the eBC mass concentrations. The aerosol was collected through the same isokinetic inlet and sampling line as for the WHOPS. eBC concentrations were logged with a time resolution of $2 \mathrm{~min}$ and averaged for the time needed to probe a certain layer. Results at a wavelength of $880 \mathrm{~nm}$ were used. During the flights a maximal attenuation of $70 \%$ and a $4 \mathrm{~L} \mathrm{~min}^{-1}$ flow rate were chosen. The data were used as retrieved by the manufacturers' firmware using an apparent MAC of $16.6 \mathrm{~m}^{2} \mathrm{~g}^{-1}$ at a wavelength of $880 \mathrm{~nm}$ for the $\mathrm{BC}$ deposited in the filter matrix. This value already accounts for the additional absorption within the filter matrix due to multi-scattering effects (Weingartner et al., 2003). Furthermore, using this value provides consistent $\mathrm{eBC}$ mass concentrations from MAAP and aethalometer, if the multi-scattering enhancement factor ( $C$ value) of the aethalometer is 3.48 and if the absorption Ångström exponent (AAE) of BC between 637 and $880 \mathrm{~nm}$ 


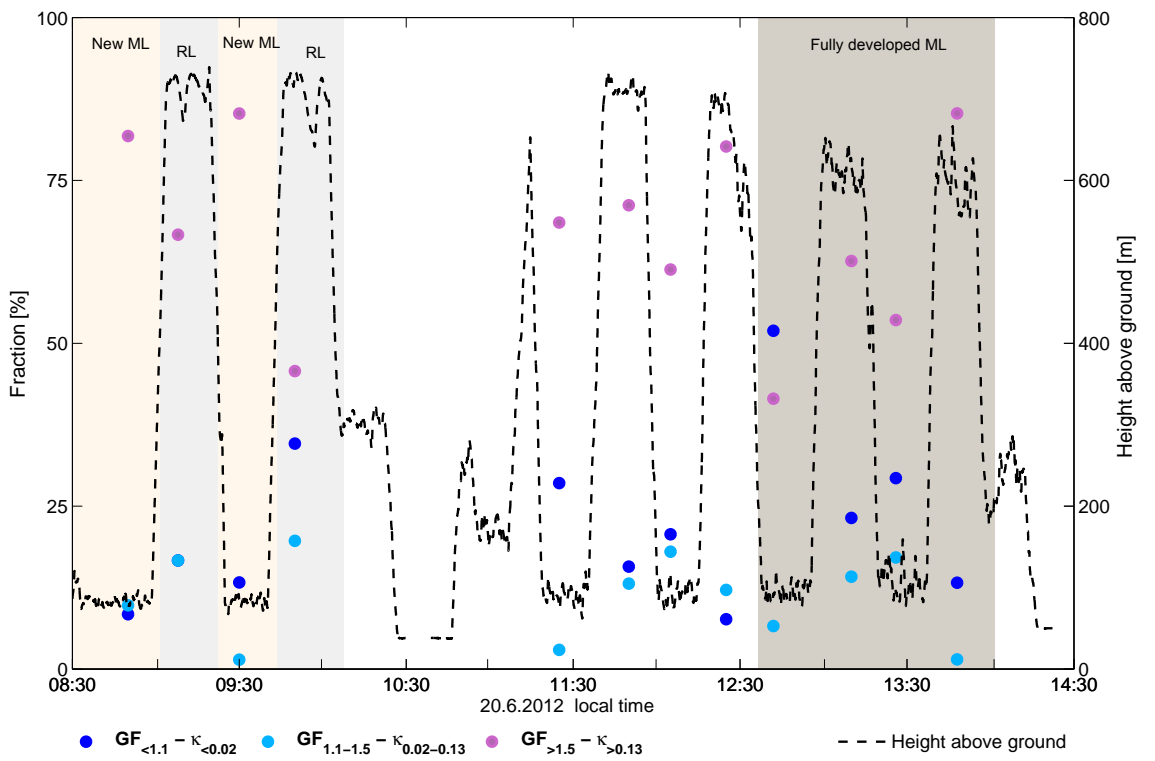

Figure 4. Time series of the mixing state of the aerosol particles (with $D_{\text {dry }}=500 \mathrm{~nm}$ ) for the height profiles in Italy on 20 June 2012 . Particles are classified into three hygroscopicity categories according to their GF: GF $<1.1,1.1<\mathrm{GF}<1.5$, GF $>1.5$, in blue, light blue and pink respectively; these are equivalent to $\kappa<0.02,0.02<\kappa<0.13$ and $\kappa>0.13$. The black, dashed line denotes the flight altitude. The labelled, coloured areas refer to the layer which was probed at the certain altitude.

wavelength is 1.0. Both should be fulfilled in good approximation (WMO/GAW, 2016; Collaud Coen et al., 2010; Sandradewi, 2008).

The chemical composition obtained from the bulk measurements of AMS and aethalometer is considered to be representative of $\mathrm{PM}_{1}$ (particulate mass with an aerodynamic diameter smaller than $1 \mu \mathrm{m}$ ), as the AMS has a transmission efficiency of close to unity for particles with vacuum aerodynamic diameters between 50 and $600 \mathrm{~nm}$ and as most eBC is expected to be present in the size range below $1 \mu \mathrm{m}$.

\section{$3 \kappa$-Köhler theory}

In order to link hygroscopicity measurements made at different RH using different instruments, it is common to use the semi-empirical $\kappa$-Köhler theory introduced by Petters and Kreidenweis (2007):

$$
\begin{gathered}
\mathrm{RH}_{\mathrm{eq}}\left(D_{\mathrm{dry}}, \mathrm{GF}, \kappa\right)=a_{\mathrm{w}}(\mathrm{GF}, \kappa) \cdot S_{\mathrm{k}}\left(\mathrm{GF}, D_{\mathrm{dry}}\right)= \\
\frac{\mathrm{GF}^{3}-1}{\mathrm{GF}^{3}-(1-\kappa)} \cdot \exp \left(\frac{4 \sigma_{\mathrm{s} / \mathrm{a}} M_{\mathrm{w}}}{\mathrm{RT} \rho_{\mathrm{w}} D_{\mathrm{dry}} \mathrm{GF}}\right) .
\end{gathered}
$$

Köhler theory relates the equilibrium $\mathrm{RH}\left(\mathrm{RH}_{\mathrm{eq}}\right)$ over a solution droplet to the product of the water activity $a_{\mathrm{w}}$ representing the Raoult term, and the factor $S_{\mathrm{k}}$ representing the Kelvin term. $D_{\text {dry }}$ describes the dry diameter, GF the growth factor (see Eq. 1), $\sigma_{\mathrm{s} / \mathrm{a}}$ is the surface tension of the solution/air interface, $M_{\mathrm{w}}$ the molecular mass of water, $R$ the ideal gas constant, $T$ the absolute temperature and $\rho_{\mathrm{W}}$ the density of water. $\kappa$ is the semi-empirical hygroscopicity parameter introduced by Petters and Kreidenweis (2007), which captures the composition dependence of the Raoult term.

To derive $\kappa$ values from GF measurements at specific RHs, the relation between $a_{\mathrm{w}}$ and GF is used as described by Petters and Kreidenweis (2007):

$\kappa_{\text {meas }}=\frac{\left(\mathrm{GF}(\mathrm{RH})^{3}-1\right) \cdot\left(1-a_{\mathrm{w}}\right)}{a_{\mathrm{w}}}$.

The subscript "meas" refers to the fact that this $\kappa$ value is based on the measured GF. The water activity was inferred from the RH and equilibrium droplet diameter $\left(D_{\text {wet }}\right)$ :

$a_{\mathrm{w}}=\frac{\mathrm{RH}}{\exp \left(\frac{4 \sigma_{\mathrm{s} / \mathrm{a}} M_{\mathrm{w}}}{R T \rho_{\mathrm{w}} D_{\mathrm{wet}}}\right)}$.

In our calculations the surface tension of water is assumed. For a composition-hygroscopicity closure, the $\kappa$ values derived from the GF measurements (WHOPS) are compared to those derived from the chemical composition measurements (AMS and aethalometer). The composition based $\kappa$ value, $\kappa_{\text {mix }}$, of a mixture was estimated from the $\kappa$ values, $\kappa_{i}$, of the pure components and the respective volume fractions, $\epsilon_{i}$, using the Zdanovskii-Stokes-Robinson (ZSR) mixing rule (Stokes and Robinson, 1966; Petters and Kreidenweis, 2007):

$\kappa_{\operatorname{mix}}=\sum_{i} \epsilon_{i} \kappa_{i}$. 
Table 1. $\kappa$ values and densities for pure compounds used for the prediction of aerosol hygroscopicity based on AMS and aethalometer or MAAP measurements.

\begin{tabular}{lrr}
\hline Compound & Density $\rho\left[\mathrm{kg} \mathrm{m}^{-3}\right]$ & $\kappa(95 \%, 500 \mathrm{~nm})$ \\
\hline$\left(\mathrm{NH}_{4}\right)_{2} \mathrm{SO}_{4}$ & 1769 & 0.458 \\
$\mathrm{NH}_{4} \mathrm{HSO}_{4}$ & 1780 & 0.575 \\
$\mathrm{H}_{2} \mathrm{SO}_{4}$ & 1830 & 0.687 \\
$\mathrm{NH}_{4} \mathrm{NO}_{3}$ & 1720 & 0.629 \\
$\mathrm{eBC}$ & 2000 & 0.000 \\
organics & $1233^{\mathrm{a}}$ & $0.08-0.13^{\mathrm{b}}$ \\
\hline
\end{tabular}

a Mean value retrieved throughout the campaign with the Kuwata et al. (2012) parametrization.

$\mathrm{b}$ Estimated from the measured O:C ratio according to Duplissy et al. (2011). See also Sect. 3.

The mass concentrations of nitrate, sulphate, ammonia, organics and chloride ions as measured by the AMS were converted to neutral salts in order to apply Eq. (5) to calculate hygroscopic properties of the aerosol particles. To do so the ion pairing mechanism described by Gysel et al. (2007) in their Eq. (2) was used. The corresponding densities as well as $\kappa$ values for the corresponding pure compounds for the prediction of the hygroscopicity parameter are summarized in Table 1. For the inorganic salts, the bulk densities were taken from literature and the $\kappa$ values were derived from ADDEM predictions (Topping et al., 2005) which is a detailed model capable of calculating growth factors of inorganic aerosols with high accuracy. The final $\kappa$ values were calculated for equilibrium solution concentrations at $a_{\mathrm{w}}=0.95$. The $\kappa$ values for the organics were inferred from the measured $\mathrm{O}: \mathrm{C}$ ratio using the relationship between $\mathrm{O}: \mathrm{C}$ and $\kappa$ value reported in Duplissy et al. (2011) for organics in atmospheric aerosols. The $\mathrm{O}: \mathrm{C}$ ratio was deduced from the HR-ToFAMS measurements using the method presented by Aiken et al. (2007). During the flight in Italy, O : C differed slightly between the three probed layers with values of $0.45 \pm 0.03$, $0.55 \pm 0.03$ and $0.50 \pm 0.05$ for the newly forming ML, the RL and the fully developed ML, respectively. The corresponding $\kappa$ values were estimated to be $0.09,0.14$ and 0.12 accordingly. The mean $\mathrm{O}: \mathrm{C}$ ratio of the organics measured at the SPC ground site was $0.60 \pm 0.03$, which translates to a $\kappa$ value of 0.17 for the organic fraction. In the Netherlands, the mean $\mathrm{O}: \mathrm{C}$ ratio of the organic matter measured by the HRToF-AMS at the ground station of Cabauw was $0.48 \pm 0.02$ and the corresponding $\kappa$ value of the organic matter was estimated to be 0.11 .

Calculations of the density of organic matter were based on a parametrization using $\mathrm{O}: \mathrm{C}$ and $\mathrm{H}: \mathrm{C}$ ratios (Kuwata et al., 2012). The mean organics' density and SD was found to be $1233 \pm 35 \mathrm{~kg} \mathrm{~m}^{-3}$. eBC was assumed to have $\kappa=0$ and a bulk density of $2000 \mathrm{~kg} \mathrm{~m}^{-3}$.

\section{Results and discussion}

\subsection{Po Valley campaign}

In the following we present hygroscopicity results recorded with the WHOPS aboard the Zeppelin NT airship. The vertical flight pattern performed on 20 June 2012 is shown in Fig. 2. During this day vertical profiles were measured within $5 \mathrm{~km}$ horizontal distance from the SPC site from $\sim 08: 30 \mathrm{LT}$ until approximately 14:00 LT with a refuel break in-between ( 10:00-11:00 LT). Two different height levels were covered at approximately 100 and $700 \mathrm{~m}$ a.g.l. On this day westerly winds and wind speeds around $2-3 \mathrm{~ms}^{-1}$ prevailed. Therefore, the air masses originated from the Po Valley plain and due to the low wind speeds the influence of local pollution was high. Figure 2 depicts the temporal evolution of potential temperature $(\Theta)$ and $\mathrm{RH}$ observed during the flight at different altitudes. The shaded area denotes the estimated mixing layer height inferred from ceilometer-Lidar data. The $\mathrm{RH}$ ranges from $30 \%$ to a maximum of $60 \%$ and shows a clear altitude dependence: during the first part of the flight the RH was always higher near the ground, while later in the day the opposite trend is visible. The evolution of $\Theta$ elucidates a clear layering during the beginning of the flight (seen as abrupt change in $\Theta$ between 100 and 700 ma.g.l.), which slowly disappears towards the last profiles. Detailed height profiles of $\Theta$ as well as mean values of RH and $\Theta$ for each height profile can be found in the supplement. The development of $\Theta$ is also consistent with the evolution of the estimated mixing layer height, which indicates that during the morning hours $(\sim 08: 30-10: 00 \mathrm{LT})$ we were able to ascend into the RL and investigate the new ML at the lower altitudes. During the second half of the flight $(\sim 12: 30-14$ :00 LT) the fully developed ML was probed at both altitudes.

\subsubsection{Mixing state inferred from hygroscopicity measurements}

Figure 3 illustrates the GF-PDFs measured by the WHOPS for different altitudes and times of day and therefore specific layers within the PBL. Each GF-PDF represents an average over the chosen time interval and altitude. The mean GF and $\kappa$ values for each panel are presented in Table 2. In general broad $\mathrm{GF}(95 \%)$ distributions with particles exhibiting GFs between 0.9 and $\sim 2.5$ can be observed throughout the flight. Vertical differences appear during IHP1/2 (Fig. 3a and c), with a more pronounced fraction of more hygroscopic particles $(\mathrm{GF}>1.5)$ in the new ML, compared to the RL. On the other hand, the fraction of particles with $\mathrm{GF}<1.1$ is more prominent in the RL. As a result, the mean hygroscopicity in the new ML is higher than in the RL reaching GF(95\%) values of $1.88 \pm 0.19$ in the former compared to $1.61 \pm 0.16$ in the latter.

The GF-PDFs measured after approximately 12:30 LT (IHP5/6) do not exhibit any clear vertical differences (Fig. 3b 
Table 2. Mean GF(95\%) and $\kappa$ values for IHP1/2 and IHP5/6 with respective accuracies. $\kappa_{\text {chem }}$ is the calculated $\kappa$ using the AMS and aethalometer measurements on board of the Zeppelin NT or AMS/MAAP combination at the SPC ground station. Besides, results for two different altitudes and the corresponding layers probed are mentioned. Additionally, the size at which the measurements are performed is stated.

\begin{tabular}{|c|c|c|c|c|c|}
\hline \multicolumn{6}{|c|}{ Zeppelin } \\
\hline \multirow[b]{2}{*}{ Size } & \multirow[b]{2}{*}{ Altitude } & \multirow[b]{2}{*}{ Layer } & \multicolumn{2}{|c|}{ WHOPS } & \multirow{2}{*}{$\begin{array}{c}\text { AMS }+ \text { Aethalometer } \\
\kappa_{\text {chem }} \\
\mathrm{PM}_{1}\end{array}$} \\
\hline & & & $\begin{array}{c}\mathrm{GF}(95 \%) \\
500 \mathrm{~nm}\end{array}$ & $\begin{array}{c}\kappa \text { WHOPS } \\
500 \mathrm{~nm}\end{array}$ & \\
\hline \multirow[t]{2}{*}{ IHP1/2 } & $100 \mathrm{~m}$ & new ML & $1.88( \pm 0.19)$ & $0.34( \pm 0.12)$ & $0.26( \pm 0.06)$ \\
\hline & $700 \mathrm{~m}$ & RL & $1.61( \pm 0.16)$ & $0.19( \pm 0.07)$ & $0.22( \pm 0.05)$ \\
\hline \multirow[t]{2}{*}{ IHP5/6 } & $100 \mathrm{~m}$ & fully developed ML & $1.49( \pm 0.15)$ & $0.14( \pm 0.06)$ & $0.19( \pm 0.04)$ \\
\hline & $700 \mathrm{~m}$ & fully developed ML & $1.63( \pm 0.16)$ & $0.20( \pm 0.08)$ & $0.20( \pm 0.04)$ \\
\hline \multicolumn{3}{|c|}{ Ground stations } & \multicolumn{3}{|c|}{ San Pietro Capofiume } \\
\hline & & & HTDMA & HTDMA & AMS + MAAP \\
\hline & & & $\mathrm{GF}(95 \%)^{*}$ & $\kappa_{\text {HTDMA }}{ }^{*}$ & $\kappa_{\text {chem }}{ }^{*}$ \\
\hline Size & & & $200 \mathrm{~nm}$ & $200 \mathrm{~nm}$ & $\mathrm{PM}_{1}$ \\
\hline IHP1/2 & & new ML & $1.61( \pm 0.22)$ & $0.19( \pm 0.04)$ & $0.31( \pm 0.08)$ \\
\hline IHP5/6 & & fully developed ML & $1.60( \pm 0.21)$ & $0.18( \pm 0.04)$ & $0.21( \pm 0.06)$ \\
\hline
\end{tabular}

* HTDMA uncertainty calculated assuming $\pm 2 \%$ accuracy in the RH measurement.

and d), indicating that in this period the Zeppelin NT flew within the fully developed ML at both altitudes. The mean $\mathrm{GF}(95 \%)$ values amount to $1.49 \pm 0.15$ and $1.63 \pm 0.16$ at 100 and 700 ma.g.l., respectively. This difference in the mean $\mathrm{GF}(95 \%)$ is for the most part caused by the outlier at $\sim 12: 45 \mathrm{LT}$, as will be shown below with Fig. 4 . It leads to subtle differences between the two altitudes with a slightly higher fraction of particles with GF $<1.1$ and a slightly lower fraction of particles with GF $>1.5$ at 100 ma.g.l. compared to $700 \mathrm{~m}$ a.g.1. When comparing the results at fixed elevation but different times (Fig. 3a vs. b and c vs. d) distinct changes are only observed at the lower altitude in the transition from the new ML to the fully developed ML, while little changed at the higher altitude in the transition from the RL to the fully developed ML. This can be explained by the differing chemical composition of the particles in these layers, with a very strong nitrate fraction in the new ML which decreases in the fully developed ML as will be discussed in more detail in Sect. 4.1.2.

Even though the GF-PDFs in Fig. 3 imply externally mixed aerosol particles, this is not necessarily the case at all times as the average of an internally mixed aerosol with variable composition could potentially yield the same result. Due to low counting statistics highly time-resolved GFPDFs are not available. For this reason, we divide the particles in three hygroscopic fractions to further investigate the time-dependent mixing state characteristics. Measurements for $D_{\text {dry }}=500 \mathrm{~nm}$ are classified as GF $<1.1$ ("nonhygroscopic"), $1.1<\mathrm{GF}<1.5$ ("moderately hygroscopic") and GF $>1.5$ ("most hygroscopic"), which correspond to ranges of $\kappa<0.02,0.02<\kappa<0.13$ and $\kappa>0.13$, respectively. Figure 4 presents the temporal evolution of the number fractions of particles in these three categories together with the flight altitude. At all times, particles are simultaneously present in at least two, mostly all three hygroscopicity ranges. This indicates an externally mixed aerosol throughout the flight. The moderately hygroscopic fraction is mostly the smallest one, accounting for less than $20 \%$ of all particles (light blue dots in Fig. 4). The most hygroscopic fraction is predominantly the largest one, accounting for $\sim 45-85 \%$ of all particles, while the non-hygroscopic fraction contributes to $\sim 9-34 \%$, whereby these values do not include the outlier. It is important to note that part of the temporal variability of the number fractions shown in Fig. 4 is caused by limited counting statistics rather than true variability of aerosol properties. However, the outlier in the fully developed ML at $\sim$ 12:45 LT with a non-hygroscopic fraction as high as $50 \%$, reflects truly different aerosol properties rather than just statistical noise.

Previous mixing state studies, based on hygroscopic growth behaviour measured with HTDMAs, found similar substantial non-hygroscopic fractions in air masses influenced by urban areas, where externally mixed black carbon (BC) was revealed as the major contributor (see e.g. Juranyi et al., 2013; Laborde et al., 2013; Lance et al., 2013). The number size distributions of freshly emitted BC particles typically peak in the diameter range around $\sim 100 \mathrm{~nm}$ (Rose et al., 2006). Therefore, externally mixed BC is less likely to give a significant contribution to particles with a diameter of $500 \mathrm{~nm}$ as probed by the WHOPS, even though a substan- 


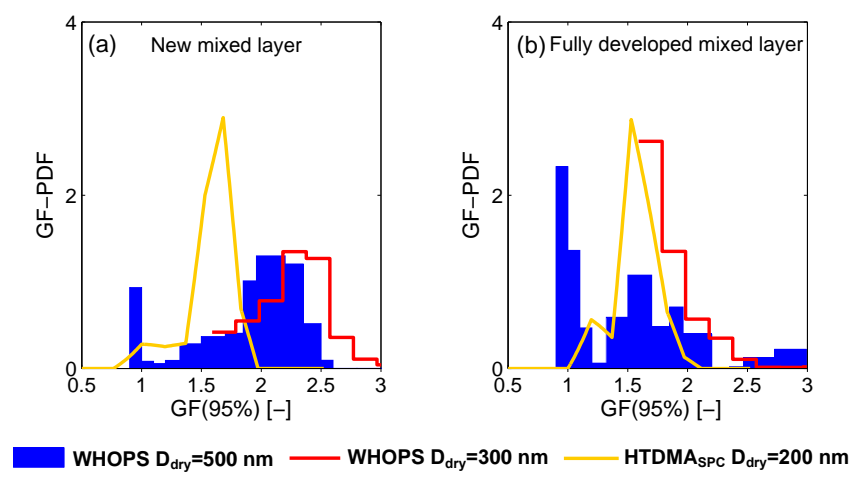

Figure 5. GF-PDF comparison between WHOPS (at 100 ma.g.1.) and HTDMA in the Po Valley on 20 June 2012. The WHOPS results were averaged from 08:30-10:00 LT for the new ML and 12:3014:00 LT for the fully developed ML, equivalent to results in Fig. 3a and $b$. The HTDMA data were averaged over the same time interval which corresponds to the mean over three full measurements per layer. Note that the WHOPS cannot reliably detect particles with $\mathrm{GF}<1.5$ and $D_{\text {dry }}=300 \mathrm{~nm}$, as described in Rosati et al. (2015). Thus, no information is available from the WHOPS measurements on the number fraction and properties of the $300 \mathrm{~nm}$ particles with $\mathrm{GF}<1.5$.

tial contribution might be detected in the lower accumulation mode size range probed by HTDMAs. Sensitivity analyses showed that it is very unlikely that non-hygroscopic externally mixed $\mathrm{BC}$ particles appear at GF $\sim 1$ in the WHOPS. However, atmospheric ageing processes, i.e. the acquisition of condensable vapours forming a shell around the $\mathrm{BC}$ core, may lead to $\mathrm{BC}$-containing particles in the size range probed by the WHOPS. These processes increase the effective density of $\mathrm{BC}$-containing particles, make their effective index of refraction more similar to that of BC-free particles (Zhang et al., 2008) and enhance their hygroscopicity (e.g. Tritscher et al., 2011; Laborde et al., 2013). A combination of these effects might result in detection of aged $\mathrm{BC}$ containing particles at $\mathrm{GF} \sim 1$. Other possible contributors for the non-hygroscopic particles measured by the WHOPS could be non-BC products from biomass burning like tar balls (Pósfai et al., 2004; Alexander et al., 2008), mineral dust (e.g. Herich et al., 2008, 2009) or biological material such as virus particles, bacteria or fungal spores (e.g. Després et al., 2012). Mineral dust is indeed a candidate as the HYSPLIT model for Saharan Dust Intrusions (specific analysis by "Spain HYSPLIT"; http://www.hysplit.uhu.es/hysplit_sa. php; not presented here) predicted Saharan dust all the way down to the lowest atmospheric layer (100 ma.g.l.) near the SPC site. However, we do not have adequate data to further investigate the source or chemical composition of the nonhygroscopic fraction.

The SPC ground station was equipped with a HTDMA to measure GF-PDFs at $\mathrm{RH}=90 \%$ in the dry diameter range below $200 \mathrm{~nm}$. At the location of SPC only the new ML and later the fully developed ML could be probed. Figure 5 compares the GF-PDFs measured at the ground site (HTDMA) with the airborne data from 100 ma.g.1. (WHOPS) separately for the new ML and the fully developed ML. As explained in Sect. 2.3.1, only GF $>1.5$ are considered for the particles with $D_{\text {dry }}=300 \mathrm{~nm}$. Comparing the two dry sizes probed by the WHOPS in the newly forming ML (red line and blue bars in Fig. 5a) reveals a strong resemblance of the GF-PDF for GF $>1.5$, except for a small shift towards larger GFs for the smaller particle size. This suggests that hygroscopic particles of these two sizes have a similar chemical composition. When, however, comparing to the HTDMA (yellow line) obvious differences appear: the distinct mode at $\mathrm{GF} \sim 1$ in the WHOPS data for the $500 \mathrm{~nm}$ particles is less pronounced in the HTDMA results. The reason might be that possible contributors to the non-hygroscopic mode are different for the larger size investigated by the WHOPS compared to the HTDMA size range. In addition, the dominant hygroscopic mode is centred at smaller GFs in the HTDMA GF-PDF, which causes a smaller mean GF and $\kappa$ value compared to the WHOPS (listed in Table 2). It is very unlikely that these differences solely arise from the size-dependent particle composition since upper accumulation mode particles at 200 and $300 \mathrm{~nm}$ are expected to be similar. The chemical analysis, which will be discussed in Sect. 4.1.2, reveals a nitrate mass fraction of $\sim 22 \%$ in the non-refractory $\mathrm{PM}_{1}$ composition. Ammonium nitrate is semi-volatile and prone to evaporation artefacts. Gysel et al. (2007) provided strong evidence for ammonium nitrate artefacts in the dry part of the HTDMA measurement, which resulted in underestimated hygroscopic GFs. The HTDMA employed in SPC featured shorter residence times in the range between 10 and $15 \mathrm{~s}$, which should minimize nitrate evaporation losses, however, they can still not be fully excluded. GF measurements done with the WHOPS are most likely less susceptible to ammonium nitrate evaporation, as the residence time in the dry part of the instrument is very short due to higher flow rates. Thus, part of the difference between the ground-based HTDMA and the airborne WHOPS in the new ML could potentially be caused by artefacts in the HTDMA, which results in a small bias of measured GFs. Another possible reason could be that the particles at the ground (measured in the surface layer) and at 100 ma.g.l. were not exactly the same due to e.g. direct influences by local emissions. This hypothesis is also supported by measurements of the particles' optical properties on this flight day, presented in Rosati et al. (2016). A comparison of the scattering and extinction coefficients between the airborne and ground-based measurements, shown in Figs. 4 and 8 in the stated paper, respectively, also illustrate differences between the two altitudes, which are independent of the hygroscopicity measurements and associated artefacts.

Figure $5 \mathrm{~b}$ displays the results for the fully developed ML. Little variation can be seen between the results for the two sizes probed by the WHOPS. The GF-PDF measured by the HTDMA is quite similar to the one found in the newly forming ML and therefore yields comparable mean hygro- 


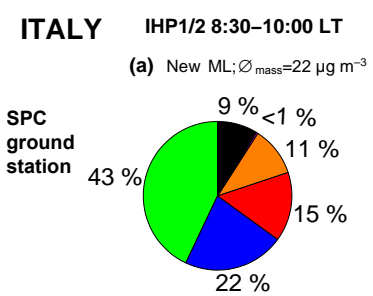

(c) New ML; $\varnothing_{\text {mass }}=21 \mu \mathrm{g} \mathrm{m}^{-3}$

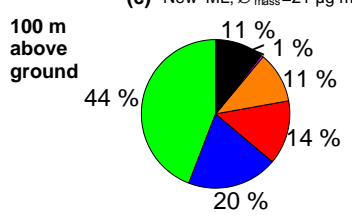

(e) RL; $\varnothing_{\text {mass }}=15 \mu \mathrm{g} \mathrm{m}^{-3}$

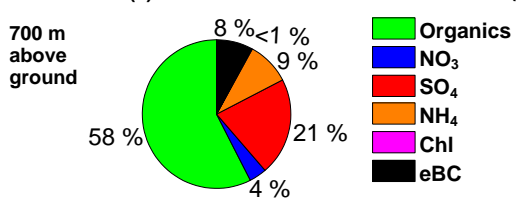

(f) Fully developed $\mathrm{ML} ; \varnothing_{\text {mass }}=13 \mu \mathrm{g} \mathrm{m}^{-3}$

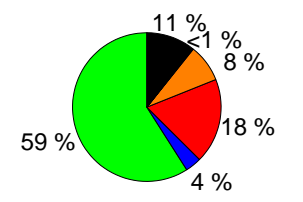

Figure 6. $\mathrm{PM}_{1}$ chemical composition results from the flight on 20 June 2012 in Italy. (a, b) show the mass fractions measured by the HR-ToF-AMS and MAAP at San Pietro Capofiume ground station; (a) was recorded during IHP1/2 whereas (b) was measured during IHP5/6. (c-f) depict the mass fractions measured by the HRToF-AMS and aethalometer on the Zeppelin. (c and e) illustrate the results for the first height profiles, (c) at 100 and (e) at $700 \mathrm{~m}$ a.g.l., while (d and f) show the results for IHP5/6 for 100 and $700 \mathrm{~m}$ a.g.l., respectively.

scopicity values (listed in Table 2). The number fraction of non-hygroscopic particles is again smaller compared to the WHOPS results. The dominant hygroscopic mode is more alike though slightly shifted to smaller GFs in the HTDMA results. Better agreement between the ground-based and airborne data for the fully developed ML, as opposed to substantial differences within the new ML, may be caused by stronger vertical mixing, thus resulting in better vertical homogeneity.

\subsubsection{Chemical composition}

Figure 6 depicts the mass fractions of carbonaceous and inorganic aerosol components in $\mathrm{PM}_{1}$, as well as the mean $\mathrm{PM}_{1}$ mass concentrations for the SPC ground station and the altitude levels probed during the Zeppelin NT flights. Organic and inorganic species were always measured by an AMS, while eBC was measured by a MAAP and an aethalometer at the SPC site and on board the Zeppelin NT, respectively. At this time of day, the highest $\mathrm{PM}_{1}$ mass concentrations were measured in new ML with mean values of 22 and $20 \mathrm{\mu g} \mathrm{m}^{-3}$ at the ground site and $\sim 100 \mathrm{ma}$ a.g.l., respectively (Figs. 6a, c and e). This is expected as most emissions from the ground, which accumulated during the night, are trapped in the new ML. The mean PM1 concentrations in the RL at

$\sim 700$ ma.g.l. (Fig. 6c), which is decoupled from the emissions at the ground, were substantially lower $\left(15 \mu \mathrm{g} \mathrm{m}^{-3}\right)$. These vertical gradients in aerosol concentration disappeared and aerosol loadings within the ML dropped as the new ML evolved to a fully developed ML in the course of the day, which resulted in stronger dilution and better vertical mixing of fresh emissions from the ground. This is confirmed by the results of the afternoon flights, when consistently 12$14 \mu \mathrm{g} \mathrm{m}^{-3}$ were measured at both flight levels and the ground station (Fig. 6b, d and f).

Overall, organic compounds were with 43 to $62 \%$ by mass the largest fraction of PM1, while the sum of inorganic species contributed between 29 and $48 \%$. The eBC mass fraction remained constantly below $12 \%$ and chloride was always negligible with less than $1 \%$. During IHP1/2 a clear difference between the mass fractions in the new ML, with a high nitrate fraction of 20-22\% (Fig. 6a and c), and the RL, with a nitrate contribution of only $5 \%$ (Fig. 6e) were observed. This increased nitrate fraction in the new ML can be explained by the accumulation of nitrate species overnight at low temperatures, which are formed in the nocturnal surface layer and are then entrained into the new ML after sunrise. The drop of the nitrate mass fraction in the fully developed ML is due to volatilization of nitrate species as a result of both increased temperature and dilution. The eBC fraction was slightly higher in the new ML compared to the RL, whereas the organics and sulphate fractions were substantially lower. During the afternoon flights (IHP5/6) in the fully developed ML, the differences in chemical composition at different altitudes disappeared as they did for the aerosol loading. The mass fractions of all species were comparable at the ground and the two flight altitudes and also very similar to those in the RL probed in the morning.

Several AMS campaigns at SPC previously determined the chemical composition at ground-level. A springtime campaign presented in Saarikoski et al. (2012) revealed a nitrate peak during the break-up of the nocturnal boundary layer, consistent with our observations, suggesting local sources of nitrate. In contrast, sulphate concentrations stayed constant throughout the day, thus indicating small local influence, again consistent with our results. Previous airborne AMS measurements showed high ammonium nitrate concentrations in the Po Valley plume, thus indicating large nitrogen oxide and ammonia sources in the Po Valley region (Crosier et al., 2007).

\subsubsection{Hygroscopicity results from airborne and ground-based measurements}

A quantitative closure study between measured chemical composition and hygroscopic growth was performed as described in Sect. 3. Figure 7 illustrates the time series of the hygroscopicity parameter as deduced from the WHOPS measurements (violet points) and the chemical composition data (blue diamonds) on board the Zeppelin NT. During IHP1/2 


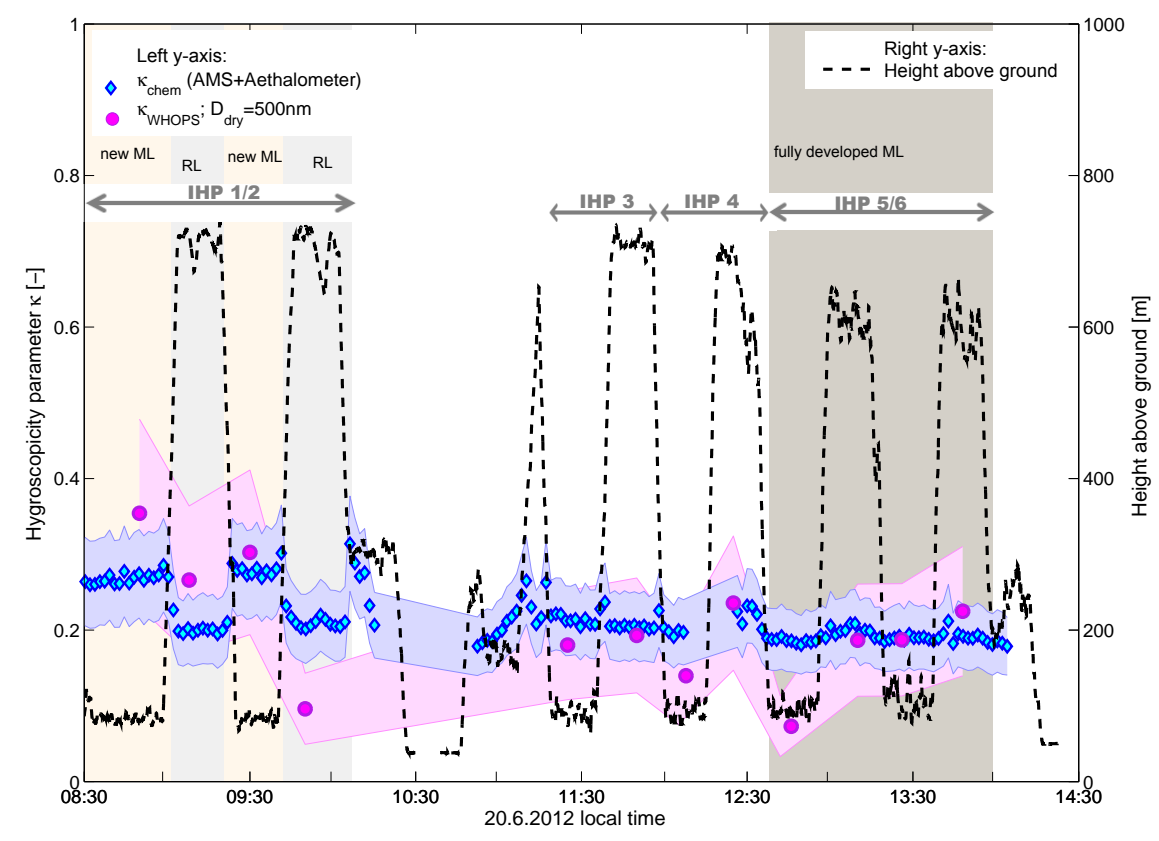

Figure 7. Time series of $\kappa$ values on 20 June 2012 in Italy. Results from chemical composition ( $\kappa_{\text {chem }}$; violet diamonds), and WHOPS for a dry selected diameter of $500 \mathrm{~nm}$ ( $\kappa_{\mathrm{WHOPS}}$; blue points) are shown. The shaded areas depict the measurement accuracy. The dashed line shows the flight altitude. In addition, the times for IHP1/2, IHP3, IHP4 and IHP5/6 are indicated. The coloured areas refer to the layer which was probed at a certain altitude and time.

$(\sim 08: 30-10: 00 \mathrm{LT})$ a clear vertical trend is seen by both techniques: higher hygroscopicity values are found close to the ground ( $\sim 100$ ma.g.l.) compared to those at elevated altitudes of $\sim 700 \mathrm{ma}$.g.l. This altitude dependence implies different layers with distinct aerosol properties, consistent with the vertical layering of the PBL indicated by $\Theta$ and the mixing layer height illustrated in Fig. 2. In the new ML the mean $\kappa$ WHOPS is found to be $0.34 \pm 0.12$, while $\kappa_{\text {chem }}$ amounts to $0.26 \pm 0.06$. These values exceed considerably the values in the RL where a $\kappa$ of $0.19 \pm 0.07$ and $0.22 \pm 0.05$ was found by the WHOPS and chemical composition, respectively. Closure is achieved between $\kappa$ WHOPS and $\kappa_{\text {chem }}$, which agree within uncertainty. Inorganic species are strongly hygroscopic, while organics and $\mathrm{BC}$ are only weakly hygroscopic and non-hygroscopic, respectively (Table 1). As a consequence, the hygroscopicity of a mixture is expected to increase with increasing inorganic fraction. Indeed, the higher GF in the new ML compared to the RL can be attributed to a higher inorganic mass fraction ( $45 \%$ compared to $30 \%$; Fig. 6 ). The variation of the inorganic fraction itself is driven by the variability of the nitrate mass fraction. Thus, the high nitrate mass fraction in the new ML is responsible for the increased particle hygroscopicity in this layer.

After $\sim$ 11:00 LT further profiles were performed. During IHP3 and IHP4 the ML had not reached its maximum height and could, therefore, be influenced by the RL or by the entrainment zone between the layers. Therefore, we discuss only the results from IHP5 and IHP6 $(\sim 12: 30$
14:00 LT), when the ML was fully developed and reached above the upper flight level. In the fully developed ML, hygroscopicity results show less variability with no clear dependence on altitude. The observed hygroscopicity values amount to $\kappa_{\text {WHOPS }}=0.14 \pm 0.06$ and $\kappa_{\text {chem }}=0.19 \pm 0.04$ at $100 \mathrm{~m}$ a.g.l. and $\kappa_{\mathrm{WHOPS}}=0.20 \pm 0.08$ and $\kappa_{\text {chem }}=0.20 \pm$ 0.04 at 700 ma.g.l., which is again closure within uncertainty (Fig. 7 and Table 2). These values appear well comparable to those measured in the RL and were characterized by a similar inorganic mass fraction of 30-34\%. An exception is the measurement taken at around 12:45 LT and 100 ma.g.l., when the mean $\kappa$ was considerably lower due to a strongly increased fraction of non-hygroscopic particles likely originating from a local source (see Fig. 4). Apart from this singular observation, the particle hygroscopic properties were homogeneous across all altitudes in the afternoon. This is in concordance with the analysis of $\Theta$ and the mixing layer height displayed in Fig. 2 which indicate the presence of a single layer below $\sim 700 \mathrm{ma}$ a.g.l. Once the fully developed ML is present vertical differences in aerosol properties are expected to disappear. Only altitude-dependent changes in temperature and $\mathrm{RH}$ can lead to alterations of the particles e.g. through phase partitioning effects.

The hygroscopicity parameters inferred from the chemical composition measurements at the SPC ground site, $\kappa_{\mathrm{chem}^{-}}$ $\mathrm{SPC}$, are $0.31 \pm 0.08$ and $0.21 \pm 0.06$ for the new ML and the fully developed ML, respectively (Table 2). This decrease of hygroscopicity is caused by the decreased nitrate and with 


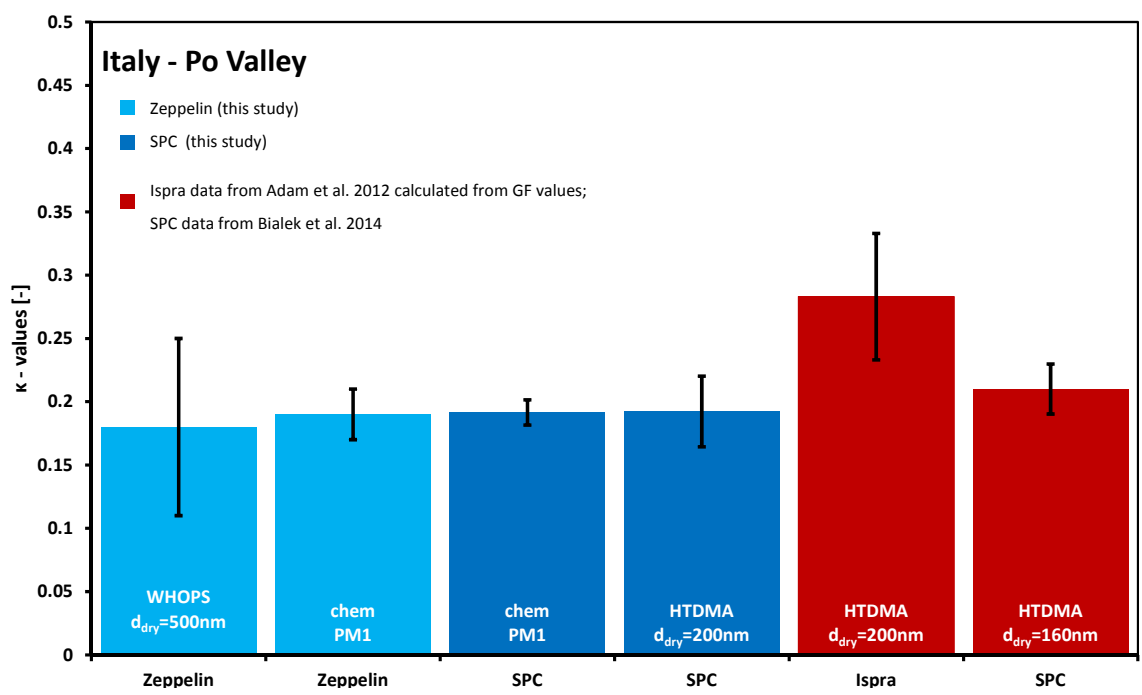

Figure 8. Inter-comparison of mean $\kappa$ values measured during this study in the Po Valley on 20 June 2012 (blue bars) compared with literature data from this area (red bars). $\kappa$ values are either derived from measured hygroscopic growth factors or chemical composition. Only results for the fully developed ML, when vertical gradients of aerosol properties are minimal, are included in the averages. This ensures comparability between the measurements taken at different altitudes. The error bars indicate the temporal variability of the observed $\kappa$ values (1 SD).

that also total inorganic mass fraction, as also seen from the airborne measurements. However, the HTDMA at the SPC site did not observe this decrease in hygroscopicity and the HTDMA-derived $\kappa$ value was significantly lower than the airborne and ground-based $\kappa_{\text {chem }}$ in the new ML. This disagreement might be a result of ammonium nitrate evaporation artefacts in the dry section of the HTDMA as already mentioned above.

\subsubsection{Comparison with previous campaigns}

The aerosol hygroscopic properties reported in this study were measured on 20 June 2012 near SPC during a predominately cloudless summer day with low wind speeds. The Po Valley has already been investigated with regard to hygroscopicity at ground-level and literature data is reported for SPC (Bialek et al., 2014) and Ispra (Adam et al., 2012; located at $45^{\circ} 49^{\prime} \mathrm{N}, 8^{\circ} 38^{\prime} \mathrm{E}$ at $209 \mathrm{~m}$ a.s.l. approximately $60 \mathrm{~km}$ north of Milan). In both locations measurements were carried out with HTDMAs. To compare our case study with these previous results only data recorded in the fully developed ML are chosen, where vertical gradients of aerosol properties are minimal. For the literature data, the time of day between 12:00 and 17:00 LT is assumed to be representative of the fully developed ML.

Mean $\kappa$ values from the different campaigns are shown in Fig. 8. All mean $\kappa$ values in SPC, shown in Fig. 8, fall into a very narrow range between 0.18 and 0.20 , independent of method and dry sizes. The value of $\kappa$ in Ispra is somewhat higher but still commensurable with the SPC results. These medium-low $\kappa$ values are typical for mixtures of ammonium salts and organic fractions of $50 \%$ or larger (see e.g. Fig. 6). The temporal variability is small and the range $\kappa=0.11$ 0.33 includes all data points within $\pm 1 \mathrm{SD}$ of the mean values. We conclude that a $\kappa$ value of $\sim 0.22$ is a good approximation for the aerosol hygroscopic properties in the fully developed ML in the Po Valley in summertime. A value of $\kappa=0.22$ should be used when estimating the cloud condensation nuclei activity in absence of hygroscopicity or composition measurements. Note that the summertime aerosol at Ispra, at the northern edge of the Po Valley, seems to be slightly more hygroscopic than in the SPC area.

\subsection{Netherlands campaign}

Here we present the findings of a Zeppelin flight on 24 May 2012 near the CESAR ground station in the Netherlands (Fig. 1). We performed a set of height profiles between approximately 11:00 and 14:00 LT, including longer legs at the following four altitudes: $\sim 100,300,500$ and $700 \mathrm{ma.g} .1$. The first height profile (NHP1) was performed from $\sim 11: 30$ to 12:45 LT and the second height profile (NHP2) from 12:45 to $13: 50$ LT. The wind direction was predominately from north-east and the wind speed on average between $\sim 3$ and $\sim 4.5 \mathrm{~m} \mathrm{~s}^{-1}$. Therefore, the probed air masses were most likely originating from the continent with some lo$\mathrm{cal} /$ regional influence due to low wind speeds. Figure 9 displays the time series of the flight altitude, estimated mixing layer height, $\mathrm{RH}$ and potential temperature $(\Theta)$. During the whole flight relatively high RH dominated (40-80\%). The pattern of $\Theta$ reveals a vertical layering during NHP1, showing a clear difference at $\sim 700 \mathrm{~m}$ a.g.l. compared to the 


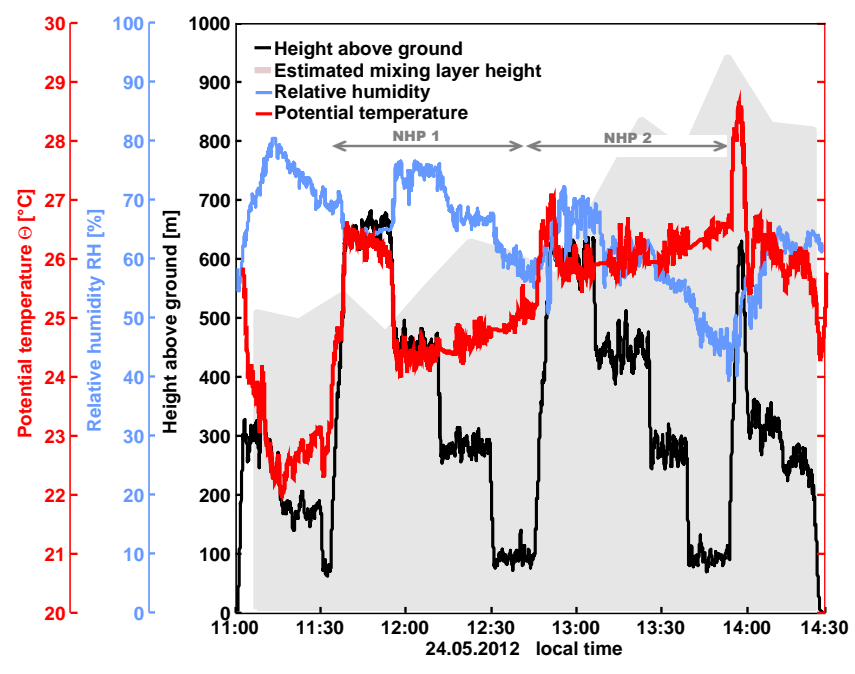

Figure 9. Overview of the flight on 24 May 2012 near the Cabauw CESAR station in the Netherlands. In black the flight altitude and in grey the estimated mixing layer height, inferred from ceilometer measurements, are presented. The red and blue lines show the potential temperature $\Theta$ and RH profiles, respectively. In addition, the different height profiles NHP1 and NHP2 are indicated.

lower altitudes. This layering is consistent with the estimated mixing layer height inferred from the ceilometer data (grey shading in Fig. 9), indicating that we managed to fly above the new ML during NHP1 at 700 ma.g.l. However, since the change in $\Theta$ and the vertical distance to the estimated mixing layer height are rather small, it is not clear whether the RL or the entrainment zone between the new ML and the RL were probed. A similar but less pronounced vertical structure in $\Theta$ can also be seen during NHP2 at 700 ma.g.l. Again, most likely the threshold range between the new ML, entrainment zone and RL were probed at this altitude. In contrast to the flights in Italy, the flights in the Netherlands started later in the day and therefore the ML had more time to develop. This is one reason why most measurements during this flight were within the new ML while none of them was for certain in the RL.

\subsubsection{Chemical composition}

Unfortunately, the airborne HR-ToF-AMS data are not available for this Zeppelin flight due to an instrument failure. At the Cabauw ground site an HR-ToF-AMS and MAAP were successfully deployed to measure the composition of $\mathrm{PM}_{1}$. A mean $\mathrm{PM}_{1}$ concentration of $15 \mu \mathrm{g} \mathrm{m}^{-3}$ was measured during NHP1, which decreased to $12 \mu \mathrm{g} \mathrm{m}^{-3}$ during NHP2 (Fig. 10). This small variation is consistent with the findings from $\Theta$ and the ceilometer indicating that the mixing layer was almost fully developed already during NHP1. Likewise, the composition also varied only little in time. Organic matter was the dominant mass fraction describing 47 and $51 \%$ of the aerosol, during NHP1 and NHP2, respectively. During

\section{NETHERLANDS \\ NHP1 11:30-12:45 LT \\ NHP2 12:45-13:50 LT}

(a) $\varnothing_{\text {mass }}=15 \mu \mathrm{g} \mathrm{m}^{-3}$

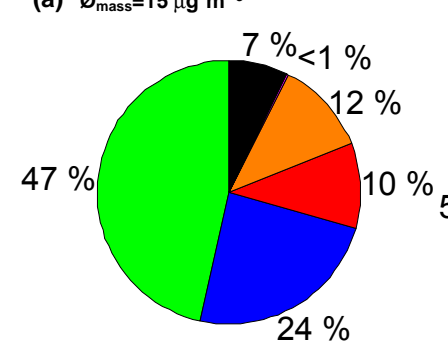

(b) क्ass $=12 \mu \mathrm{g} \mathrm{m}^{-3}$
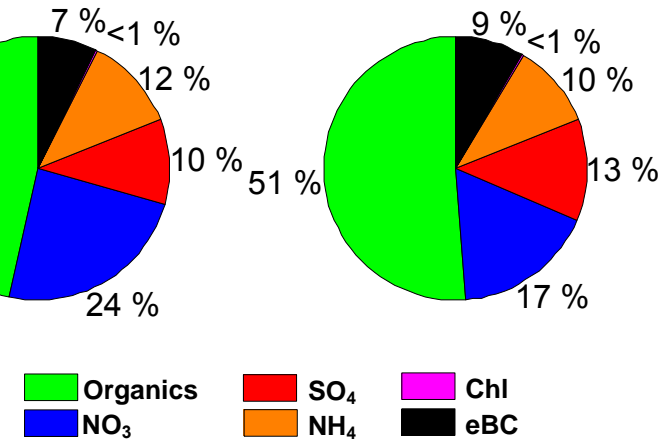

Figure 10. Ground measurements of the aerosol particle chemical composition at the Cabauw tower during NHP1 and NHP2 on 24 May 2012. HR-ToF-AMS and MAAP results are combined for the total aerosol mass. Also, the averaged mass concentrations during the profile periods are stated.

both profiles nitrate constituted the second most abundant fraction accounting for 24 and $17 \%$, while sulphate made up 10 and $13 \%$ and $\mathrm{eBC} 7$ and $9 \%$ of the total mass, during NHP1 and NHP2, respectively.

\subsubsection{Hygroscopicity results and mixing state}

The airborne hygroscopicity results from the WHOPS instrument are presented as GF-PDFs (Fig. 11), number fractions in different hygroscopicity classes (Fig. 12) and hygroscopicity parameters $(\kappa$; Fig. 13). All three figures show little variability of the aerosol hygroscopic properties with altitude. This is expected given the previously discussed layering of the PBL, which indicates that mainly the fully developed ML was probed. Small changes in aerosol hygroscopicity are also in agreement with almost constant chemical composition at the ground site (Fig. 10). Furthermore, compositionhygroscopicity closure is achieved, i.e. the composition derived $\kappa\left(\kappa_{\text {chem }}=0.28 \pm 0.06\right)$ agrees well with the GFderived $\kappa(\kappa$ WHOPS $=0.25-0.29$; see Table 3$)$. This good agreement should be taken with some care, as for example sea salt can potentially play a role in the Cabauw area, which is not quantitatively detected by the HR-ToF-AMS. However, in the next section we will show that the sea salt influence was likely low during the flight presented in this study.

The appearance of particles with $\mathrm{GF}(95 \%)$ across the whole range from around 0.9 to 3.2 in the GF-PDFs for a dry particle diameter of $500 \mathrm{~nm}$ indicates that the aerosol was externally mixed (Fig. 11). In order to further investigate the time evolution of the mixing state, the GF-PDFs were split into three hygroscopicity classes (equivalent to the ranges chosen for the flight in the Po Valley). The dominant fraction of particles was more hygroscopic $(\mathrm{GF}>1.5)$ mak- 
NETHERLANDS
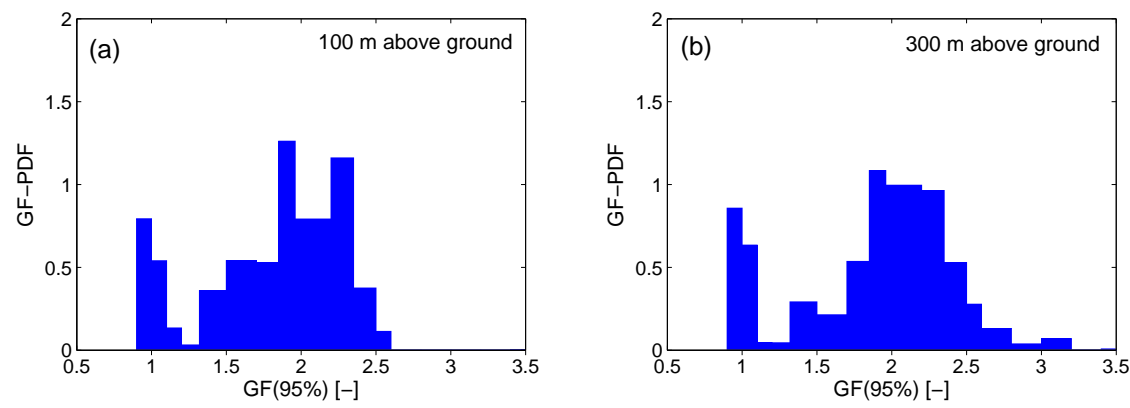

$\mathrm{D}_{\mathrm{dry}}=500 \mathrm{~nm}$ humidified
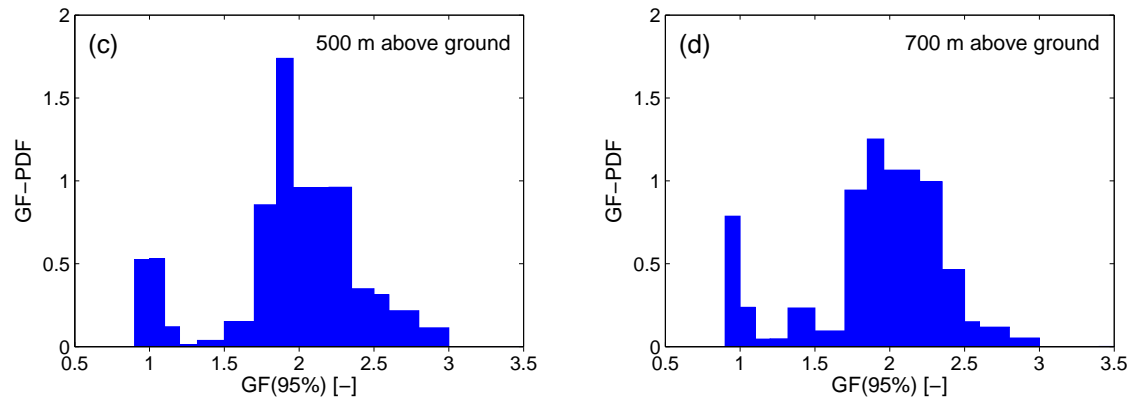

Figure 11. GF-PDFs recorded near Cabauw on 24 May 2012 at four different altitudes: approximately 100, 300 , 500 and 700 ma.g.1. seen in panels (a-d), respectively. Every curve is the mean over the two flown profiles NHP1 and NHP2.

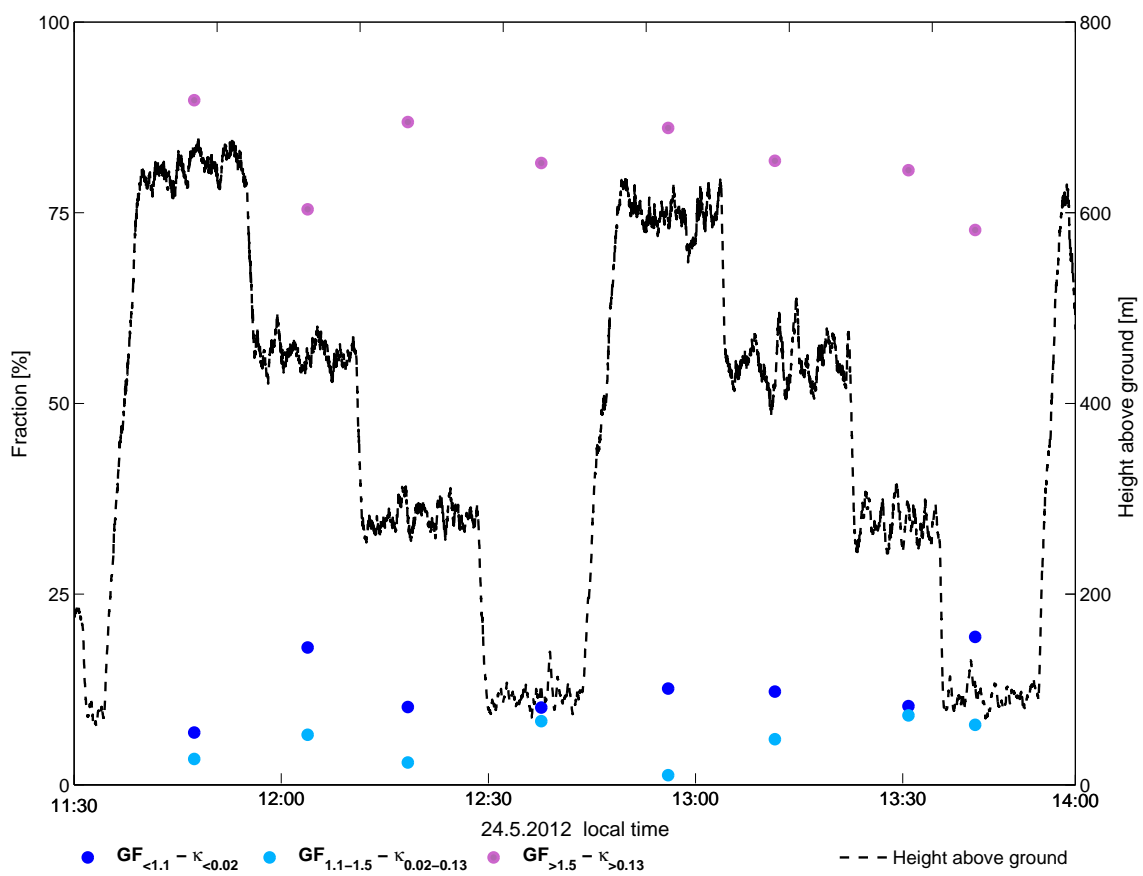

Figure 12. Time evolution of the mixing state of the aerosol particles (with $D_{\text {dry }}=500 \mathrm{~nm}$ ) for the height profiles near Cabauw on 24 May 2012. Particles are classified into three hygroscopicity categories according to their GF (equally defined as for Fig. 4): GF $<1.1$, $1.1<\mathrm{GF}<1.5, \mathrm{GF}>1.5$, in blue, light blue and pink respectively; these correspond to $\kappa<0.02,0.02<\kappa<0.13$ and $\kappa>0.13$. 


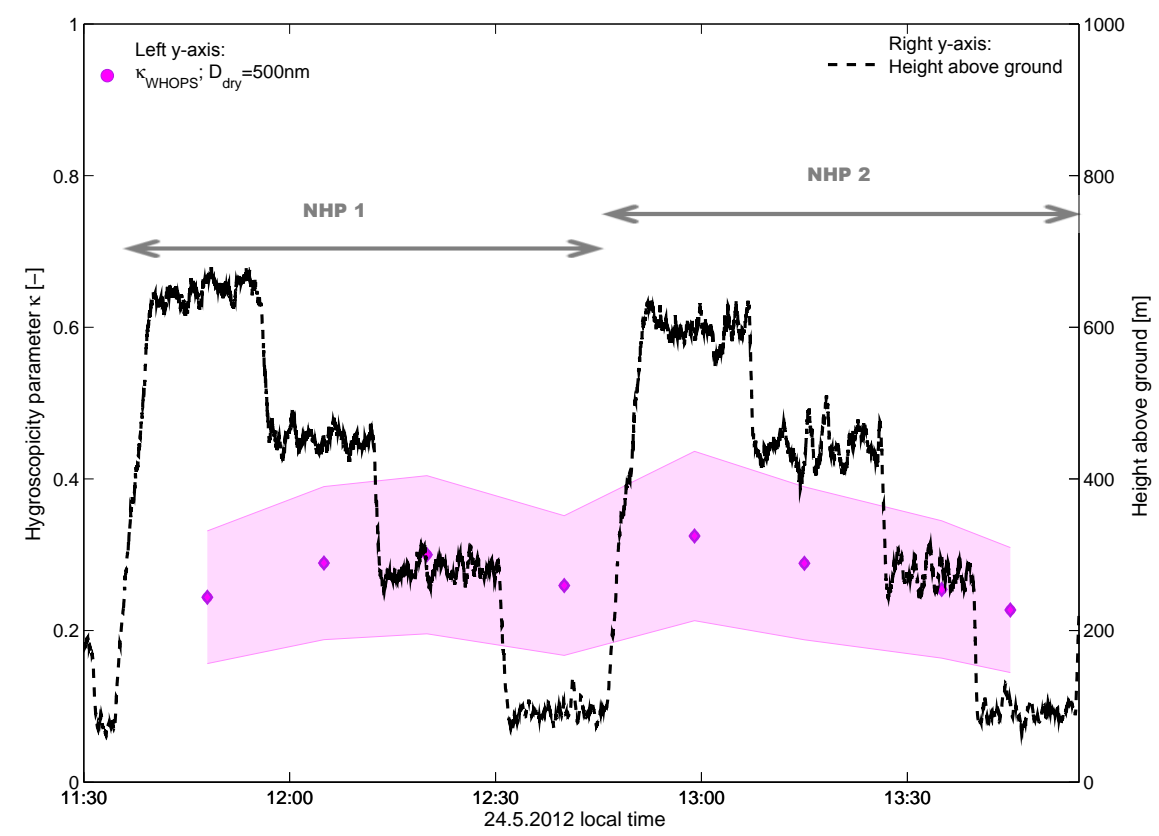

Figure 13. Time series of $\kappa$ values retrieved during the flight on 24 May 2012. WHOPS results for a dry diameter of $500 \mathrm{~nm}$ are presented. The measurement accuracy is shown as the shaded area. Additionally, the flight altitude is indicated.

Table 3. Mean GF and $\kappa$ values for NHP1/2 with respective accuracies are presented. For the WHOPS measurements at four different altitudes are shown. $\kappa_{\text {chem }}$ is calculated from the Cabauw ground site combining AMS and MAAP results.

\begin{tabular}{lccc}
\hline \multicolumn{3}{c}{ Zeppelin } \\
\hline \multirow{3}{*}{ Size } & Altitude & GF $(95 \%)$ & $\kappa$ WHOPS \\
& & $500 \mathrm{~nm}$ & $500 \mathrm{~nm}$ \\
\hline NHP1/2 & $100 \mathrm{~m}$ & $1.84( \pm 0.18)$ & $0.25( \pm 0.09)$ \\
& $300 \mathrm{~m}$ & $1.91( \pm 0.19)$ & $0.28( \pm 0.10)$ \\
& $500 \mathrm{~m}$ & $1.92( \pm 0.19)$ & $0.29( \pm 0.10)$ \\
& $700 \mathrm{~m}$ & $1.93( \pm 0.19)$ & $0.29( \pm 0.10)$ \\
\hline Ground station & Cabauw \\
\hline \multicolumn{3}{c}{ AMS + MAAP } \\
Size & \multicolumn{3}{c}{ PMem $_{1}$} \\
\hline NHP1/2 & $0.28( \pm 0.06)$ \\
\hline
\end{tabular}

ing up $82 \%$ (72-89\%) of the particles, while $12 \%(7-18 \%)$ were non-hygroscopic $(\mathrm{GF}<1.1)$ and only $6 \%(1-9 \%)$ of the particles fell into the range $1.1<\mathrm{GF}<1.5$ (Fig. 12). The number fraction of non-hygroscopic particles observed in Cabauw was about half of the corresponding fraction in the Po Valley. Despite being only half, it was still larger than expected as no evidence for Saharan dust influence was observed in contrast to the Po Valley. However, we do not have any supporting data to further assess whether it was dust or whether other candidates such as biological material, tar balls or $\mathrm{BC}$ containing particles contributed to the non-hygroscopic fraction (see also Sect. 4.1.1). The variability of aerosol hygroscopicity with altitude was found to be small but consistently decreasing from $\mathrm{GF}(95 \%)$ values of $1.93 \pm 0.19$ at $700 \mathrm{ma}$ a.g.l. to $1.84 \pm 0.18$ at $\sim 100 \mathrm{ma.g} .1$. (see also Table 3). Figure 13 shows that this trend applies for every flight altitude change after $\sim 12: 15 \mathrm{LT}$. One possible explanation for this could be temperature-dependent partitioning of ammonium nitrate (which is strongly hygroscopic; see Table 1). Morgan et al. (2010a) previously reported an increasing nitrate fraction with increasing altitude in the Cabauw area, which was observed between measurements at the ground site and $\sim 2000 \mathrm{~m}$ a.g.l.

In summary, the convective mixing within the fully developed ML leads to almost constant aerosol hygroscopicity as a function of altitude except for small effects from potential repartitioning of semi-volatile species. This shows that ground-based measurements provide valid information about the aerosol properties for the well-mixed part of the column aloft.

\subsubsection{Comparison to previous campaigns}

Airborne hygroscopicity measurements with the WHOPS from a different Zeppelin flight on 22 May 2012 close to Cabauw have previously been reported in Rosati et al. (2015). This flight was characterized by sampling two distinct air mass types with and without substantial influence of sea salt aerosol. Figure 14 illustrates a GF-PDF comparison 
from results from 22 and 24 May 2012 (Rosati et al., 2015). Generally speaking, the GF-PDFs are similar in that all feature a minor peak at $\mathrm{GF} \sim 1$ and a dominant peak in the range $\mathrm{GF}=1.9-2.5$. A clear increase of particles with $\mathrm{GF}>2.5$ was observed on 22 May for the air mass with sea salt (SS) influence, as opposed to the air mass without sea salt (nonSS) influence. The results from this flight on 24 May 2012 resemble more closely the non-SS case, thus indicating that this flight was not substantially influenced by sea salt.

Zieger et al. (2011) presented hygroscopicity data for the Cabauw region in 2009 achieved by a humidified nephelometer ("Wet-Neph") and an HTDMA. From this campaign we selected two representative dates for SS (8 July 2009) and non-SS (14 July 2009) conditions. In order to ensure comparability only data between 12:00 and 17:00 LT are included as they were all recorded in the fully developed ML. Figure 15 presents mean $\kappa$ values determined with different methods on different days, all in the Cabauw region in the fully developed ML. The literature data in Fig. 15 clearly show that the aerosol at Cabauw is more hygroscopic under the influence of sea salt aerosol, with mean $\kappa$ values between 0.33 and 0.5 . The variability between the three methods (WHOPS, WetNeph and HTDMA) is partially related to the increasing sea salt fraction with increasing particle size (Zieger et al., 2011). For conditions without SS influence, literature reports lower $\kappa$ values between 0.23 and 0.31 , which matches the results of this study well. Thus, the flight of this study can be considered to be representative of the ML in the Cabauw area when air masses without substantial SS influence prevail. The $\kappa$ values in Fig. 15 can be used as estimates for aerosol hygroscopicity at the Cabauw site when no hygroscopicity measurement is available. The uncertainty of the estimate can be reduced by distinguishing between air masses with and without SS influence.

\section{Conclusions}

During morning hours, the PBL is often separated into sublayers, which contain particles of different age and chemical history. Within the PEGASOS project a Zeppelin NT was deployed in the Po Valley, Italy, and in the Netherlands close to Cabauw, permitting one to investigate the evolving layers inside the PBL with regard to the aerosol particles' chemical composition, hygroscopic growth and mixing state. This unique airborne data set was further combined with concurrent ground-based measurements to get a more complete picture of the particles' properties throughout the flights. During the flight on 20 June 2012 in the Po Valley, different layers in the PBL could be explored: the residual layer (RL), the new mixed layer (ML) and the fully developed ML. Major differences in chemical composition and hygroscopicity were found in the first hours of the day when the new ML entrained air from the nocturnal boundary layer. During this time $\mathrm{PM}_{1}$ nitrate concentrations represent $20 \%$ of the to-

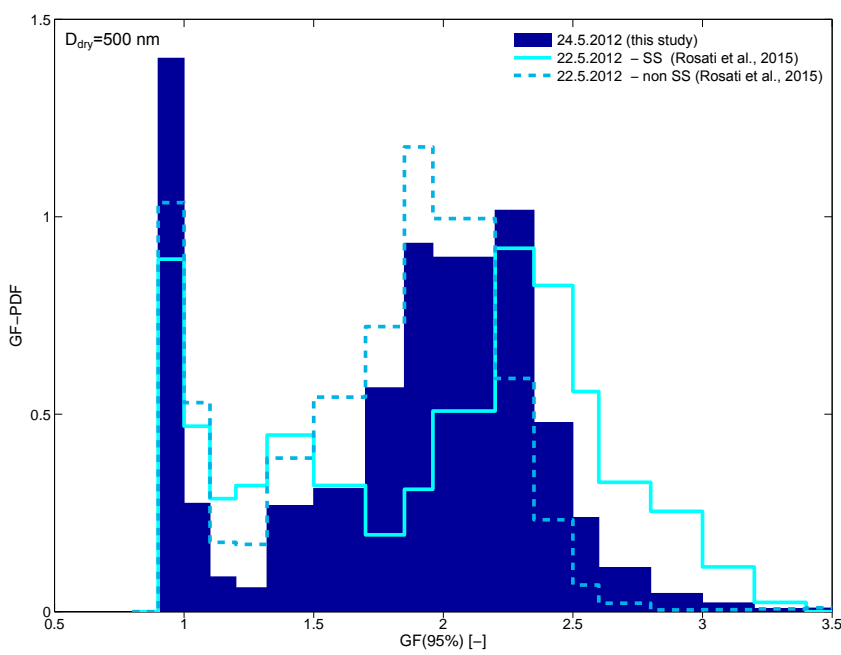

Figure 14. Comparison of GF-PDFs recorded with the WHOPS on board of the Zeppelin for two different flight days: 24 May 2012 (this study) and on 22 May 2012 (Rosati et al., 2015). Both flights were located close to Cabauw and results are representative for particles with $D_{\text {dry }}=500 \mathrm{~nm}$.

tal aerosol mass leading to hygroscopicity parameters $(\kappa)$ of $0.34 \pm 0.12$ and $0.26 \pm 0.06$ measured by the WHOPS (at $D_{\text {dry }}=500 \mathrm{~nm}$ ) and retrieved from the $\mathrm{PM}_{1}$ chemical composition, respectively. This nitrate peak can be explained by the accumulation of nitrate species during the night which decreases during the day by partitioning to the gas-phase and dilution in the new ML. $\kappa$ values in the RL and fully developed ML are comparable for the physical and chemical analysis approach yielding lower values around 0.19. The fully developed ML, which was probed during the last flight hours, showed no characteristic altitude dependence. Ground-based observations compare well to low-altitude, airborne results, confirming the higher $\kappa$ values early in the morning compared to later in the day. This underlines the problematic estimation of altitude-specific data from surface measurements during the development of the ML, which could not take into account different aerosol particle properties in the RL. In contrast, ground-based data can yield reasonable results for the fully developed ML. The mixing state of the aerosols was investigated using the WHOPS, revealing an external mixture over the whole day at all altitudes. The major fraction $(67 \%)$ experienced $\mathrm{GF}(95 \%)>1.5$, while $22 \%$ were nonhygroscopic $(\mathrm{GF}(95 \%)<1.1)$.

In the Netherlands only the fully developed ML or the entrainment zone between ML and RL were sampled. Therefore, air masses did not strongly feature altitudedependent aerosol properties. The hygroscopic fraction $(\mathrm{GF}(95 \%)>1.5)$ was more pronounced than in the Po Valley amounting to $82 \%$ of the total aerosol. Again an externally mixed aerosol was found, where $12 \%$ of the particles showed $\operatorname{GF}(95 \%)<1.1$. The mean $\kappa$ values deduced 


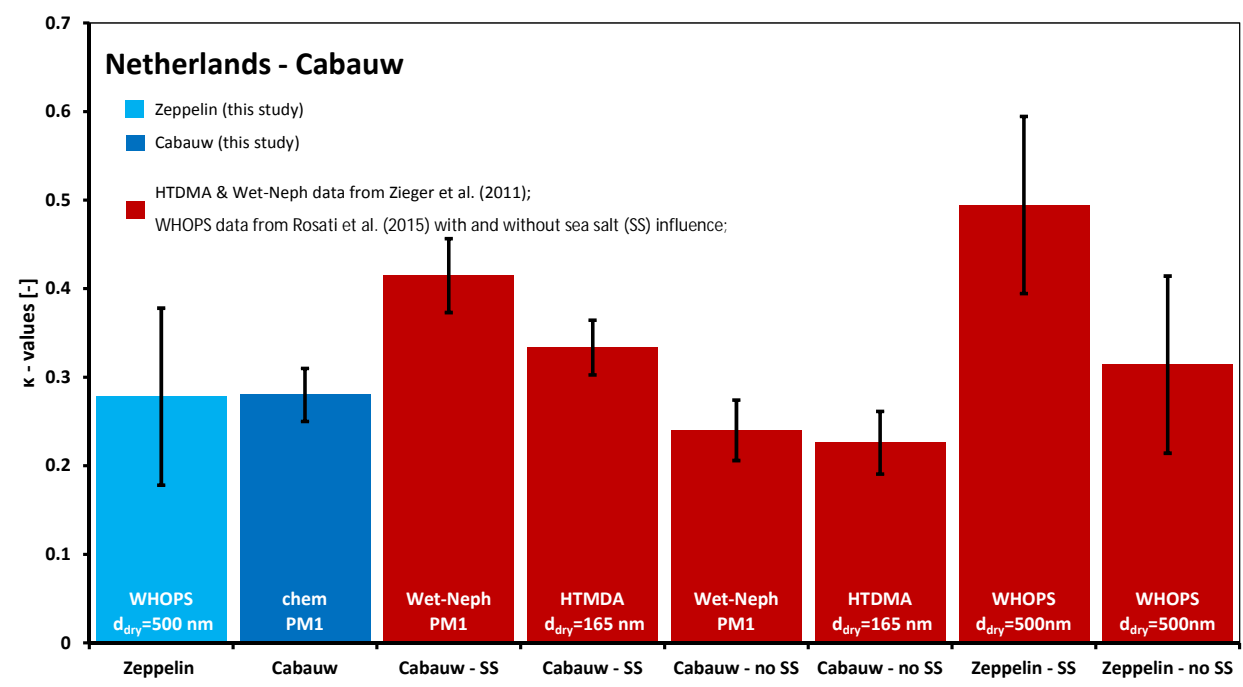

Figure 15. Inter-comparison of mean $\kappa$ values and their temporal variability measured on board of the Zeppelin NT (light blue bar) and at the ground (dark blue bar) during the PEGASOS campaign on 24 May 2012 in the Netherlands. Additionally, results from two separate campaigns reported in the literature are shown (red bars). For the flight described in Rosati et al. (2015) two separate bars are presented dividing results in sea salt (SS) and non-sea salt (non-SS) influenced periods. In the same way results from Zieger et al. (2011) are split in SS and non-SS periods for measurements performed with two different techniques.

from the WHOPS and the ground-based chemical composition data are very similar amounting to $0.28 \pm 0.10$ and $0.28 \pm 0.06$, respectively.

When comparing results from Italy and the Netherlands it appears that the non-hygroscopic aerosol fraction $(\mathrm{GF}(95 \%)<1.1)$ is more dominant in the Po Valley, which could be explained by enhanced Saharan dust intrusions which are more likely to occur in Italy. HYSPLIT calculations support this hypothesis observing dust intrusions even in the lowest layer of $100 \mathrm{ma}$ a.g.l. on this specific flight day. On the other hand, the fraction of particles with $\mathrm{GF}(95 \%)>1.5$ in the fully developed ML is considerably higher in the Netherlands. Overall chemical composition measurements feature the organics fraction as the most dominant one both in Italy and the Netherlands, describing approximately $50 \%$ of the total aerosol mass.

\section{The Supplement related to this article is available online at doi:10.5194/acp-16-7295-2016-supplement.}

Acknowledgements. This work was supported by the EC project PEGASOS, funded by the European Commission under the Framework Programme 7 (FP7-ENV-2010-265148). We thank all PEGASOS participants for the excellent team work during the campaigns. Additionally we thank F. Holland for the analysis and maintenance of all meteorological and GPS data on the Zeppelin. We also thank R. Tillmann, J. Bialek and C. O'Dowd for their contributions to the paper. Then we thank I. Pap and K. Weinhold for their help in maintaining the MAAP instrument at the SPC ground site. M. Gysel was supported by the ERC under grant 615922-BLACARAT. The field work at the ground-based stations was partly funded by Regione Emilia Romagna as part of the SUPERSITO project (DRG no. 428/10). The research leading to these results has also received funding from the European Union's Seventh Framework Programme's (FP7/2007-2013) BACCHUS project (grant agreement no. 603445). Part of the in situ aerosol observations used in this study have received funding from the European Union Seventh Framework Programme (FP7/2007-2013) ACTRIS under grant agreement no. 262254.

Edited by: N. Mihalopoulos

\section{References}

Adam, M., Putaud, J. P., Martins dos Santos, S., Dell'Acqua, A., and Gruening, C.: Aerosol hygroscopicity at a regional background site (Ispra) in Northern Italy, Atmos. Chem. Phys., 12, 57035717, doi:10.5194/acp-12-5703-2012, 2012.

Alexander, D. T. L., Crozier, P. A., and Anderson, J. R.: Brown carbon spheres in east asian outflow and their optical properties, Science, 321, 833-836, doi:10.1126/science.1155296, 2008.

Allan, J. D., Delia, A. E., Coe, H., Bower, K. N., Alfarra, M., Jimenez, J. L., Middlebrook, A. M., Drewnick, F., Onasch, T. B., Canagaratna, M. R., Jayne, J. T., and Worsnop, D. R.: A generalised method for the extraction of chemically resolved mass spectra from Aerodyne aerosol mass spectrometer data, J. Aerosol Sci., 35, 909-922, doi:10.1016/j.jaerosci.2004.02.007, 2004.

Angelini, F., Barnaba, F., Landi, T., Caporaso, L., and Gobbi, G.: Study of atmospheric aerosols and mixing layer by LIDAR, Radiat. Prot. Dosim., 137, 275-279, 2009. 
Bialek, J., Dall Osto, M., Vaattovaara, P., Decesari, S., Ovadnevaite, J., Laaksonen, A., and O'Dowd, C.: Hygroscopic and chemical characterisation of Po Valley aerosol, Atmos. Chem. Phys., 14, 1557-1570, doi:10.5194/acp-14-1557-2014, 2014.

Bohren, C. F. and Huffman, D. R.: Absorption and Scattering of Light by Small Particles, Wiley-VCH Verlag GmbH, New York, NY, USA, doi:10.1002/9783527618156.fmatter, 2007.

Boucher, O., Randall, D., Artaxo, P., Bretherton, C., Feingold, G., Forster, P., Kerminen, V.-M., Kondo, Y., Liao, H., Lohmann, U., Rasch, P., Satheesh, S. K., Sherwood, S., Stevens, B. and Zhang, X. Y.: Clouds and Aerosols, in: Climate Change 2013: The Physical Science Basis. Contribution of Working Group I to the Fifth Assessment Report of the Intergovernmental Panel on Climate Change, edited by: Stocker, T. F., Qin, D., Plattner, G.-K., Tignor, M., Allen, S. K., Boschung, J., Nauels, A., Xia, Y., Bex, V., and Midgley, P. M., Cambridge University Press, Cambridge, United Kingdom and New York, NY, USA, Chapter 7, 571-658, doi:10.1017/CBO9781107415324.016, 2013.

Collaud Coen, M., Weingartner, E., Apituley, A., Ceburnis, D., Fierz-Schmidhauser, R., Flentje, H., Henzing, J. S., Jennings, S. G., Moerman, M., Petzold, A., Schmid, O., and Baltensperger, U.: Minimizing light absorption measurement artifacts of the Aethalometer: evaluation of five correction algorithms, Atmos. Meas. Tech., 3, 457-474, doi:10.5194/amt-3457-2010, 2010.

Crosier, J., Allan, J. D., Coe, H., Bower, K. N., Formenti, P., and Williams, P. I.: Chemical composition of summertime aerosol in the Po Valley (Italy), northern Adriatic and Black Sea, Q. J. Roy. Meteor. Soc., 133, 61-75, doi:10.1002/qj.88, 2007.

DeCarlo, P. F., Kimmel, J. R., Trimborn, A., Northway, M. J., Jayne, J. T., Aiken, A. C., Gonin, M., Fuhrer, K., Horvath, T., Docherty, K. S., Worsnop, D. R., and Jimenez, J. L.: Fielddeployable, high-resolution, time-of-flight aerosol mass spectrometer, Anal. Chem., 78, 8281-8289, doi:10.1021/ac061249n, 2006.

Després, V., Huffman, J., Burrows, S., Hoose, C., Safatov, A., Buryak, G., Fröhlich-Nowoisky, J., Elbert, W., Andreae, M., Pöschl, U., and Jaenicke, R.: Primary biological aerosol particles in the atmosphere: a review, Tellus B, 64, 15598, doi:10.3402/tellusb.v64i0.15598, 2012.

Di Giuseppe, F., Riccio, A., Caporaso, L., Bonafé, G., Gobbi, G., and Angelini, F.: Automatic detection of atmospheric boundary layer height using ceilometer backscatter data assisted by a boundary layer model, Q. J. Roy. Meteor. Soc., 138, 649-663, 2012.

Duplissy, J., DeCarlo, P. F., Dommen, J., Alfarra, M. R., Metzger, A., Barmpadimos, I., Prevot, A. S. H., Weingartner, E., Tritscher, T., Gysel, M., Aiken, A. C., Jimenez, J. L., Canagaratna, M. R., Worsnop, D. R., Collins, D. R., Tomlinson, J., and Baltensperger, U.: Relating hygroscopicity and composition of organic aerosol particulate matter, Atmos. Chem. Phys., 11, 1155-1165, doi:10.5194/acp-11-1155-2011, 2011.

Gysel, M., Crosier, J., Topping, D. O., Whitehead, J. D., Bower, K. N., Cubison, M. J., Williams, P. I., Flynn, M. J., McFiggans, G. B., and Coe, H.: Closure study between chemical composition and hygroscopic growth of aerosol particles during TORCH2, Atmos. Chem. Phys., 7, 6131-6144, doi:10.5194/acp7-6131-2007, 2007.
Gysel, M., McFiggans, G., and Coe, H.: Inversion of tandem differential mobility analyser (TDMA) measurements, J. Aerosol Sci., 40, 134-151, doi:10.1016/j.jaerosci.2008.07.013, 2009.

Haeffelin, M., Angelini, F., Morille, Y., Martucci, G., Frey, S., Gobbi, G., Lolli, S., O’Dowd, C., Sauvage, L., Xueref-Rémy, I., Wastine, B., and Feist, D.: Evaluation of mixing-height retrievals from automatic profiling lidars and ceilometers in view of future integrated networks in Europe, Bound.-Lay. Meteorol., 143, 4975, doi:10.1007/s10546-011-9643-z, 2012.

Haij, M., Wauben, W., and Klein-Baltink, H.: Continuous mixing layer height determination using the LD-40 ceilometer: a feasibility study, KNMI Scientific Report 07-01, available at: http://edepot.wur.nl/62411 (last access: 2 June 2016) 2007.

Hegg, D. A., Covert, D. S., Jonsson, H., and Covert, P. A.: An instrument for measuring size-resolved aerosol hygroscopicity at both sub- and super-micron sizes, Aerosol Sci. Tech., 41, 873883, doi:10.1080/02786820701506955, 2007.

Herich, H., Kammermann, L., Gysel, M., Weingartner, E., Baltensperger, U., Lohmann, U., and Cziczo, D. J.: In situ determination of atmospheric aerosol composition as a function of hygroscopic growth, J. Geophys. Res.-Atmos., 113, D16213, doi:10.1029/2008JD009954, 2008.

Herich, H., Tritscher, T., Wiacek, A., Gysel, M., Weingartner, E., Lohmann, U., Baltensperger, U., and Cziczo, D. J.: Water uptake of clay and desert dust aerosol particles at sub- and supersaturated water vapor conditions, Phys. Chem. Chem. Phys., 11, 7804-7809, doi:10.1039/b901585j, 2009.

Hersey, S. P., Sorooshian, A., Murphy, S. M., Flagan, R. C., and Seinfeld, J. H.: Aerosol hygroscopicity in the marine atmosphere: a closure study using high-time-resolution, multiple-RH DASHSP and size-resolved C-ToF-AMS data, Atmos. Chem. Phys., 9, 2543-2554, doi:10.5194/acp-9-2543-2009, 2009.

Hersey, S. P., Craven, J. S., Metcalf, A. R., Lin, J., Lathem, T., Suski, K. J., Cahill, J. F., Duong, H. T., Sorooshian, A., Jonsson, H. H., Shiraiwa, M., Zuend, A., Nenes, A., Prather, K. A., Flagan, R. C., and Seinfeld, J. H.: Composition and hygroscopicity of the Los Angeles Aerosol: CalNex, J. Geophys. Res.Atmos., 118, 3016-3036, doi:10.1002/jgrd.50307, 2013.

Jurányi, Z., Tritscher, T., Gysel, M., Laborde, M., Gomes, L., Roberts, G., Baltensperger, U., and Weingartner, E.: Hygroscopic mixing state of urban aerosol derived from sizeresolved cloud condensation nuclei measurements during the MEGAPOLI campaign in Paris, Atmos. Chem. Phys., 13, 64316446, doi:10.5194/acp-13-6431-2013, 2013.

Kamilli, K. A., Poulain, L., Held, A., Nowak, A., Birmili, W., and Wiedensohler, A.: Hygroscopic properties of the Paris urban aerosol in relation to its chemical composition, Atmos. Chem. Phys., 14, 737-749, doi:10.5194/acp-14-737-2014, 2014.

Kammermann, L., Gysel, M., Weingartner, E., and Baltensperger, U.: 13-month climatology of the aerosol hygroscopicity at the free tropospheric site Jungfraujoch (3580 ma.s.1.), Atmos. Chem. Phys., 10, 10717-10732, doi:10.5194/acp-1010717-2010, 2010.

Kuwata, M., Zorn, S. R., and Martin, S. T.: Using elemental ratios to predict the density of organic material composed of carbon, hydrogen, and oxygen, Environ. Sci. Technol., 46, 787-794, doi:10.1021/es202525q, 2012.

Laborde, M., Crippa, M., Tritscher, T., Jurányi, Z., Decarlo, P. F., Temime-Roussel, B., Marchand, N., Eckhardt, S., Stohl, A., Bal- 
tensperger, U., Prévôt, A. S. H., Weingartner, E., and Gysel, M.: Black carbon physical properties and mixing state in the European megacity Paris, Atmos. Chem. Phys., 13, 5831-5856, doi:10.5194/acp-13-5831-2013, 2013.

Lance, S., Raatikainen, T., Onasch, T. B., Worsnop, D. R., Yu, X.Y., Alexander, M. L., Stolzenburg, M. R., McMurry, P. H., Smith, J. N., and Nenes, A.: Aerosol mixing state, hygroscopic growth and cloud activation efficiency during MIRAGE 2006, Atmos. Chem. Phys., 13, 5049-5062, doi:10.5194/acp-13-50492013, 2013.

Liu, B. Y. H., Pui, D. Y. H., Whitby, K. T., Kittelson, D. B., Kousaka, Y., and McKenzie, R. L.: Aerosol mobility chromatograph - new detector for sulfuric - acid aerosols, Atmos. Environ., 12, 99-104, doi:10.1016/0004-6981(78)90192-0, 1978.

McMurry, P. H. and Stolzenburg, M. R.: On the sensitivity of particle-size to relative humidity for los angeles aerosols, Atmos. Environ., 23, 497-507, doi:10.1016/0004-6981(89)905933, 1989 .

Middlebrook, A. M., Bahreini, R., Jimenez, J. L., and Canagaratna, M. R.: Evaluation of composition-dependent collection efficiencies for the Aerodyne aerosol mass spectrometer using field data, Aerosol Sci. Tech., 46, 258-271, doi:10.1080/02786826.2011.620041, 2012.

Mie, G.: Beiträge zur Optik trüber Medien, speziell kolloidaler Metallösungen, Ann. Phys.-Berlin, 330, 377-445, doi:10.1002/andp.19083300302, 1908.

Morgan, W. T., Allan, J. D., Bower, K. N., Capes, G., Crosier, J., Williams, P. I., and Coe, H.: Vertical distribution of sub-micron aerosol chemical composition from North-Western Europe and the North-East Atlantic, Atmos. Chem. Phys., 9, 5389-5401, doi:10.5194/acp-9-5389-2009, 2009.

Morgan, W. T., Allan, J. D., Bower, K. N., Esselborn, M., Harris, B., Henzing, J. S., Highwood, E. J., Kiendler-Scharr, A., McMeeking, G. R., Mensah, A. A., Northway, M. J., Osborne, S., Williams, P. I., Krejci, R., and Coe, H.: Enhancement of the aerosol direct radiative effect by semi-volatile aerosol components: airborne measurements in North-Western Europe, Atmos. Chem. Phys., 10, 8151-8171, doi:10.5194/acp-10-8151-2010, 2010a.

Morgan, W. T., Allan, J. D., Bower, K. N., Highwood, E. J., Liu, D., McMeeking, G. R., Northway, M. J., Williams, P. I., Krejci, R., and Coe, H.: Airborne measurements of the spatial distribution of aerosol chemical composition across Europe and evolution of the organic fraction, Atmos. Chem. Phys., 10, 4065-4083, doi:10.5194/acp-10-4065-2010, 2010b.

Müller, T., Henzing, J. S., de Leeuw, G., Wiedensohler, A., Alastuey, A., Angelov, H., Bizjak, M., Collaud Coen, M., Engström, J. E., Gruening, C., Hillamo, R., Hoffer, A., Imre, K., Ivanow, P., Jennings, G., Sun, J. Y., Kalivitis, N., Karlsson, H., Komppula, M., Laj, P., Li, S.-M., Lunder, C., Marinoni, A., Martins dos Santos, S., Moerman, M., Nowak, A., Ogren, J. A., Petzold, A., Pichon, J. M., Rodriquez, S., Sharma, S., Sheridan, P. J., Teinilä, K., Tuch, T., Viana, M., Virkkula, A., Weingartner, E., Wilhelm, R., and Wang, Y. Q.: Characterization and intercomparison of aerosol absorption photometers: result of two intercomparison workshops, Atmos. Meas. Tech., 4, 245-268, doi:10.5194/amt-4-245-2011, 2011.

Petters, M. D. and Kreidenweis, S. M.: A single parameter representation of hygroscopic growth and cloud condensation nucleus activity, Atmos. Chem. Phys., 7, 1961-1971, doi:10.5194/acp-71961-2007, 2007.

Petzold, A., and Schönlinner, M.: Multi-angle absorption photometry a new method for the measurement of aerosol light absorption and atmospheric black carbon, J. Aerosol Sci., 35, 421-441, doi:10.1016/j.jaerosci.2003.09.005, 2004.

Petzold, A., Schloesser, H., Sheridan, P., Arnott, W., Ogren, J., and Virkkula, A.: Evaluation of multiangle absorption photometry for measuring aerosol light absorption, Aerosol Sci. Tech., 39, 4051, doi:10.1080/027868290901945, 2005.

Pratt, K. A. and Prather, K. A.: Aircraft measurements of vertical profiles of aerosol mixing states, J. Geophys. Res.-Atmos., 115 , D11305, doi:10.1029/2009JD013150, 2010.

Pósfai, M., Gelencsér, A., Simonics, R., Arató, K., Li, J., Hobbs, P. V., and Buseck, P. R.: Atmospheric tar balls: Particles from biomass and biofuel burning, J. Geophys. Res.-Atmos., 109, D06213, doi:10.1029/2003JD004169, 2004.

Putaud, J.-P., Dingenen, R. V., Alastuey, A., Bauer, H., Birmili, W., Cyrys, J., Flentje, H., Fuzzi, S., Gehrig, R., Hansson, H., Harrison, R., Herrmann, H., Hitzenberger, R., Hüglin, C., Jones, A., Kasper-Giebl, A., Kiss, G., Kousa, A., Kuhlbusch, T., Löschau, G., Maenhaut, W., Molnar, A., Moreno, T., Pekkanen, J., Perrino, C., Pitz, M., Puxbaum, H., Querol, X., Rodriguez, S., Salma, I., Schwarz, J., Smolik, J., Schneider, J., Spindler, G., ten Brink, H., Tursic, J., Viana, M., Wiedensohler, A., and Raes, F.: A European aerosol phenomenology - 3: Physical and chemical characteristics of particulate matter from 60 rural, urban, and kerbside sites across Europe, Atmos. Environ., 44, 1308-1320, doi:10.1016/j.atmosenv.2009.12.011, 2010.

Rosati, B., Wehrle, G., Gysel, M., Zieger, P., Baltensperger, U., and Weingartner, E.: The white-light humidified optical particle spectrometer (WHOPS) - a novel airborne system to characterize aerosol hygroscopicity, Atmos. Meas. Tech., 8, 921-939, doi:10.5194/amt-8-921-2015, 2015.

Rosati, B., Herrmann, E., Bucci, S., Fierli, F., Cairo, F., Gysel, M., Tillmann, R., Größ, J., Gobbi, G. P., Di Liberto, L., Di Donfrancesco, G., Wiedensohler, A., Weingartner, E., Virtanen, A., Mentel, T. F., and Baltensperger, U.: Studying the vertical aerosol extinction coefficient by comparing in situ airborne data and elastic backscatter lidar, Atmos. Chem. Phys., 16, 4539-4554, doi:10.5194/acp-16-4539-2016, 2016.

Rose, D., Wehner, B., Ketzel, M., Engler, C., Voigtländer, J., Tuch, T., and Wiedensohler, A.: Atmospheric number size distributions of soot particles and estimation of emission factors, Atmos. Chem. Phys., 6, 1021-1031, doi:10.5194/acp-6-1021-2006, 2006.

Rubach, F.: Aerosol Processes in the Planetary Boundary Layer: High resolution Aerosol Mass Spectrometry on a Zeppelin NT Airship, PhD thesis, Bergische Universität Wuppertal, Germany, 2013.

Saarikoski, S., Carbone, S., Decesari, S., Giulianelli, L., Angelini, F., Canagaratna, M., Ng, N. L., Trimborn, A., Facchini, M. C., Fuzzi, S., Hillamo, R., and Worsnop, D.: Chemical characterization of springtime submicrometer aerosol in Po Valley, Italy, Atmos. Chem. Phys., 12, 8401-8421, doi:10.5194/acp12-8401-2012, 2012.

Sandradewi, J., Prévôt, A. S. H., Weingartner, E., Schmidhauser, R., Gysel, M., and Baltensperger, U.: A study of wood burning and traffic aerosols in an Alpine valley using a 
multi-wavelength Aethalometer, Atmos. Environ., 42, 101-112, doi:10.1016/j.atmosenv.2007.09.034, 2008.

Sorooshian, A., Hersey, S. P., Brechtel, F. J., Corless, A., Flagan, R. C., and Seinfeld, J. H.: Rapid, size-resolved aerosol hygroscopic growth measurements: differential aerosol sizing and hygroscopicity spectrometer probe (DASH-SP), Aerosol Sci. Tech., 42, 445-464, doi:10.1080/02786820802178506, 2008.

Stokes, R. H. and Robinson, R. A.: Interactions in aqueous nonelectrolyte solutions, I. Solute - solvent equilibria, J. Phys. Chem.US, 70, 2126, doi:10.1021/j100879a010, 1966.

Stull, R.: An Introduction to Boundary Layer Meteorology, Kluwer Academic Publisher, Dordrecht, the Netherlands, 1988.

Swietlicki, E., Hansson, H. C., Hameri, K., Svenningsson, B., Massling, A., McFiggans, G., McMurry, P. H., Petaja, T., Tunved, P., Gysel, M., Topping, D., Weingartner, E., Baltensperger, U., Rissler, J., Wiedensohler, A., and Kulmala, M.: Hygroscopic properties of submicrometer atmospheric aerosol particles measured with H-TDMA instruments in various environments - a review, Tellus B, 60, 432-469, doi:10.1111/j.16000889.2008.00350.x, 2008.

Topping, D. O., McFiggans, G. B., and Coe, H.: A curved multicomponent aerosol hygroscopicity model framework: Part 1 - Inorganic compounds, Atmos. Chem. Phys., 5, 1205-1222, doi:10.5194/acp-5-1205-2005, 2005.

Tritscher, T., Juranyi, Z., Martin, M., Chirico, R., Gysel, M., Heringa, M. F., DeCarlo, P. F., Sierau, B., Prevot, A. S. H., Weingartner, E., and Baltensperger, U.: Changes of hygroscopicity and morphology during ageing of diesel soot, Environ. Res. Lett., 6, 034026, doi:10.1088/1748-9326/6/3/034026, 2011.
Weingartner, E., Saathoff, H., Schnaiter, M., Streit, N., Bitnar, B., and Baltensperger, U.: Absorption of light by soot particles: determination of the absorption coefficient by means of aethalometers, J. Aerosol Sci., 34, 1445-1463, doi:10.1016/S00218502(03)00359-8, 2003.

WMO/GAW: Aerosol measurements procedures guidelines and recommendations, second edition, World Meteorological Organization, Geneva, Switzerland, 2016.

Wu, Z. J., Poulain, L., Henning, S., Dieckmann, K., Birmili, W., Merkel, M., van Pinxteren, D., Spindler, G., Müller, K., Stratmann, F., Herrmann, H., and Wiedensohler, A.: Relating particle hygroscopicity and $\mathrm{CCN}$ activity to chemical composition during the HCCT-2010 field campaign, Atmos. Chem. Phys., 13, 79837996, doi:10.5194/acp-13-7983-2013, 2013.

Zhang, R., Khalizov, A. F., Pagels, J., Zhang, D., Xue, H., and McMurry, P. H.: Variability in morphology, hygroscopicity, and optical properties of soot aerosols during atmospheric processing, P. Natl. Acad. Sci. USA, 105, 10291-10296, doi:10.1073/pnas.0804860105, 2008.

Zieger, P., Weingartner, E., Henzing, J., Moerman, M., de Leeuw, G., Mikkilä, J., Ehn, M., Petäjä, T., Clémer, K., van Roozendael, M., Yilmaz, S., Frieß, U., Irie, H., Wagner, T., Shaiganfar, R., Beirle, S., Apituley, A., Wilson, K., and Baltensperger, U.: Comparison of ambient aerosol extinction coefficients obtained from in-situ, MAX-DOAS and LIDAR measurements at Cabauw, Atmos. Chem. Phys., 11, 2603-2624, doi:10.5194/acp-11-2603-2011, 2011. 